\title{
Periaxonal and nodal plasticity modulate action potential conduction in the adult mouse brain
}

Authors: Carlie L Cullen ${ }^{1 \#}$, Renee E Pepper ${ }^{1 \#}$, Mackenzie T Clutterbuck ${ }^{1}$, Kimberley A Pitman $^{1}$, Viola Oorschot ${ }^{2}$, Loic Auderset ${ }^{1}$, Alexander D Tang ${ }^{3}$, Georg Ramm², Ben Emery ${ }^{4}$, Jennifer Rodger ${ }^{3,5}$, Renaud B Jolivet ${ }^{6}$, Kaylene M Young ${ }^{1,7^{*}}$

\author{
Affiliations: \\ Western Australia, Perth, AUS. \\ Science University, Portland, OR, USA. \\ Switzerland \\ ${ }^{7}$ Lead Contact \\ \#These authors contributed equally
*Correspondence to: kaylene.young@utas.edu.au
}

${ }^{1}$ Menzies Institute for Medical Research, University of Tasmania, Hobart, AUS.

${ }^{2}$ Ramaciotti Centre for Cryo-Electron Microscopy, Monash University, Melbourne, AUS

${ }^{3}$ Experimental and Regenerative Neurosciences, School of Biological Sciences, University of

${ }^{4}$ Jungers Center for Neurosciences Research, Department of Neurology, Oregon Health and

${ }^{5}$ Perron Institute for Neurological and Translational Research, Perth, AUS.

${ }^{6}$ Département de Physique Nucléaire et Corpusculaire, University of Geneva, Geneva,

Summary: Central nervous system myelination increases action potential conduction velocity, however, it is unclear how myelination is coordinated to ensure the temporally precise arrival of action potentials, and facilitate information processing within cortical and associative circuits. Here, we show that mature myelin remains plastic in the adult mouse brain and can undergo subtle structural modifications to influence action potential arrival times. Repetitive transcranial magnetic stimulation and spatial learning, two stimuli that modify neuronal activity, alter the length of the nodes of Ranvier and the size of the periaxonal space within active brain regions. This change in the axon-glial configuration is independent of oligodendrogenesis and tunes conduction velocity to increase the synchronicity of action potential transit.

Keywords: myelin, node of Ranvier, oligodendrocyte, spatial learning, transcranial magnetic stimulation, periaxonal space, action potential, conduction velocity, computational modelling 


\section{Introduction:}

Within the central nervous system (CNS), oligodendrocytes elaborate myelin internodes to facilitate the rapid and saltatory conduction of action potentials and provide vital trophic support to axons via the periaxonal space (Simons and Nave, 2015). The speed of action potential conduction along individual axons is dependent on the molecular and structural parameters of the axon, including its diameter; the presence, length and thickness of myelin internodes; the length of the nodes of Ranvier; and the relative density of ion channels clustered at the nodes and paranodes (Arancibia- Carcamo et al., 2017; Ford et al., 2015; Freeman et al., 2016; Halter and Clark, 1993; Seidl, 2014; Young et al., 2013). Recently, it was also shown that axial conduction through the periaxonal space is important for the saltatory propagation of action potentials (Cohen et al., 2020). As even seemingly small changes in conduction velocity have the potential to significantly impact neuronal network function, by altering spike-time arrival or by disrupting the synchrony of brain wave rhythms (Pajevic et al., 2014), these structures must be precisely established and retain a degree of plasticity.

Oligodendrogenesis and myelination commence late in development (Jakovcevski et al., 2009; Kessaris et al., 2006; Lu et al., 2002) and peak prior to adolescence, however, new oligodendrocytes are generated throughout life (Dimou et al., 2008; Hill et al., 2018; Hughes et al., 2018; Rivers et al., 2008; Yeung et al., 2014; Young et al., 2013) to replace dying cells (Koenning et al., 2012; Yeung et al., 2014) and add myelin to previously unmyelinated or partially myelinated axons (Hill et al., 2018). The process of myelination is significantly influenced by experience, as social isolation early in life reduces the addition of myelin to the prefrontal cortex (Liu et al., 2012; Makinodan et al., 2012), and reducing visual input (monocular deprivation) shortens the myelin internodes elaborated by oligodendrocytes in the affected optic nerve (Etxeberria et al., 2016; Osanai et al., 2018). Conversely, in the adult brain, increasing neuronal activity, either by direct neuronal stimulation or through learning a 
new skill, promotes oligodendrogenesis and myelination of the activated circuits (Cullen et al., 2019; Gibson et al., 2014; Li et al., 2010; McKenzie et al., 2014; Mitew et al., 2018; SampaioBaptista et al., 2013).

In the developing zebrafish spinal cord, the extension and retraction of internodes is regulated by distinct patterns of calcium activity within the nascent myelin sheaths, and this can be partially regulated by neuronal activity (Baraban et al., 2018; Krasnow et al., 2018). In the mammalian brain, periodic and mitochondria-derived calcium transients can be detected within myelin sheaths that increase in frequency at the peak of cortical myelination and during remyelination in the adult mouse brain (Battefeld et al., 2019). Even after maturation, oligodendrocytes retain some capacity for internode remodeling, with a subset of internodes extending or retracting over time (Hill et al., 2018; Hughes et al., 2018). This capacity is perhaps best highlighted by the extension of established myelin sheaths to occupy an adjacent segment of recently demyelinated axon, following the ablation of a single myelinating oligodendrocyte in the zebrafish spinal cord (Auer et al., 2018). However, the extent to which mature oligodendrocytes remodel their internodes in the healthy brain, in response to specific physiological stimuli such as altered neuronal activity, has not been explored. Herein, we show that modulating neuronal activity, either artificially through repetitive transcranial magnetic stimulation (rTMS) or physiologically through learning, has no effect on gross internode length, but results in bi-directional adaptive changes to the axo-myelinic ultrastructure, that fine tune action potential conduction speed in the adult mouse brain.

\section{Results:}

The gross myelinating morphology of mature oligodendrocytes does not change with iTBS

We have previously shown that non-invasive, low-intensity rTMS (Li-rTMS), delivered in an intermittent theta burst (iTBS) pattern, promotes the survival and maturation of new oligodendrocytes within the primary motor cortex (M1) (Cullen et al., 2019). To determine 
whether the non-invasive stimulation of M1 could induce adaptive changes in myelinating oligodendrocytes, we labelled a subset of mature cortical oligodendrocytes by giving a single dose of tamoxifen to adult (P83) Plp-CreER :: Tau-mGFP transgenic mice, one week prior to commencing Li-rTMS (see STAR methods). Following 14 days of sham-stimulation or iTBS we analyzed the morphology of mGFP-labelled myelinating oligodendrocytes within M1 (Figure 1A-B) and the underlying corpus callosum (CC; Figure 1C-D). More specifically, we measured the length of $\mathrm{mGFP}^{+}$internodes that were flanked on each end by contactinassociated protein $(\text { CASPR })^{+}$paranodes (Figure 1C-D). We found that internodes elaborated by pre-existing $\mathrm{mGFP}^{+} \mathrm{M} 1$ oligodendrocytes were shorter (range $\sim 2-118 \mu \mathrm{m}, 30.28 \pm 0.77$ mean $\pm \mathrm{SD}$; Figure 1E, F) than those elaborated in the CC (range $\sim 10-104 \mu \mathrm{m}, 50.68 \pm 1.02$ mean $\pm \mathrm{SD}$; Figure 1G, H), but that iTBS did not alter the average length (Figure 1F, H) or length distribution (Figure 1E, G) of internodes in either region. The density of mGFP internodes within the CC (Figure S1) made it impossible to attribute internodes to any single cell within this region. However, we were able to determine the number of internodes maintained by individual oligodendrocytes within M1 and found that this was also unchanged by iTBS (sham: $29 \pm 3$; iTBS: $28 \pm 2$, mean \pm SEM, t-test $\mathrm{p}=0.62, \mathrm{n}=13$ and 12 cells respectively), indicating that iTBS does not lead to detectable changes in the gross myelinating morphology of mature oligodendrocytes.

\section{iTBS shortens nodes of Ranvier}

At the end of each internode, anchoring proteins expressed by the myelin loops, such as neurofascin 155, interact with the axonal proteins contactin and CASPR to form paranodes (Bhat et al., 2001; Charles et al., 2002; Klingseisen et al., 2019; Peles et al., 1997; Sherman et al., 2005). These paranodal junctions maintain voltage gated sodium channels $\left(\mathrm{Na}_{\mathrm{v}} 1.6\right)$ at the nodes of Ranvier (Freeman et al., 2016; Freeman et al., 2015; Suzuki et al., 2004). It has been suggested that node length is plastic, and may be modulated in response to altered neuronal 
activity to fine tune action potential propagation in accordance with information processing needs (Arancibia-Carcamo et al., 2017; Ford et al., 2015), however this has not yet been confirmed experimentally.

To determine whether iTBS affects specific axonal domains, we immunolabelled coronal brain sections from iTBS and sham stimulated animals to visualize paranodes (CASPR) and nodes of Ranvier $\left(\mathrm{Na}_{\mathrm{v}} 1.6\right)$ (Figure 2A-D). By identifying regions of dense $\mathrm{Na}_{\mathrm{v}} 1.6$ staining that were clearly flanked by abutting $\mathrm{CASPR}^{+}$paranodes, we quantified the length of individual nodes within M1 (Figure 2A-B, E) and the underlying CC (Figure 2C-D, F). We found that 14 days of iTBS treatment shifted node length distribution towards shorter nodes within both M1 (Figure 2E) and the CC (Figure 2G), which corresponded to a $\sim 19 \%$ reduction in average node length in M1 (Figure 2F) and a $\sim 16 \%$ decrease in the $\mathrm{CC}$ (Figure 2H). This shortening of the node length was not accompanied by a change in paranode length (or length distribution) (Figure S2A-D). To confirm the effect of iTBS on node length, we also performed high resolution stimulated emission depletion (STED) microscopy to visualize callosal nodes $\left(\mathrm{Na}_{\mathrm{v}} 1.6\right)$ and paranodes (CASPR) in a separate cohort of animals following 14 days of iTBS or sham stimulation (Figure S2E-F). Consistent with our initial observations, we found that iTBS shifted the node length distribution towards shorter nodes (Figure S2G), corresponding to a reduction of $\sim 18 \%$ in average node length per mouse within the $\mathrm{CC}$ (Figure $\mathbf{S 2 H}$ ).

To determine whether node length was stable after stimulation ceased, we measured the length of individual nodes 7 days later (14+7 days). We found that nodes within M1 of iTBS mice returned to a similar average length and distribution as sham stimulated mice (Figure 2I, J), suggestive of bidirectional plasticity. However, within the $\mathrm{CC}$ the length distribution remained significantly shifted towards shorter nodes (Figure $2 \mathbf{K}$ ), corresponding to a $\sim 20 \%$ decrease in 
average node length (Figure 2L), perhaps suggesting that nodal changes are more long-lived in the white matter relative to the grey matter.

\section{Spatial learning lengthens nodes of Ranvier}

Learning physiologically modulates neuronal activity (Benchenane et al., 2010; Dupret et al., 2010; Dupret et al., 2013; Negrón-Oyarzo et al., 2018) and motor learning has been shown to promote oligodendrogenesis and increase myelination within the corpus callosum (SampaioBaptista et al., 2013; Xiao et al., 2016), but it is not clear whether mature oligodendrocytes respond to learning. Two weeks after tamoxifen administration (at P60), we trained adult (P74) Plp-CreER :: Tau-mGFP transgenic mice to learn the hippocampal dependent radial arm maze task (RAM; see STAR methods and Figure S3A, C). The subset of Plp-CreER :: Tau-mGFP transgenic mice that were exposed to the maze, but were not trained to learn the location of food rewards, are referred to as no-learning controls (Figure S3B). Following 14 days of nolearning (NL) or learning (L), we analyzed the morphology of mGFP-labelled myelinating oligodendrocytes within the hippocampal fimbria (Figure 3A-B), a major white matter tract that connects both hippocampi with subcortical and cortical regions including the thalamus and prefrontal cortex (Jin and Maren, 2015; Wyss et al., 1980). Due to the density of mGFP labelled internodes within the fimbria (Figure S1C), it was not possible to reliably attribute internodes to a single cell, however, by measuring the length of individual $\mathrm{mGFP}^{+}$internodes (green), flanked by $\mathrm{CASPR}^{+}$(blue) paranodes (Figure 3C), we determined that internodes within the fimbria were $\sim 5-109 \mu \mathrm{m}$ in length (inset Figure 3D), and that spatial learning had no effect on the average length or length distribution of internodes in this region (Figure 3DE).

To determine whether learning induced nodal plasticity we quantified the length of nodes $\left(\mathrm{Na}_{\mathrm{v}} 1.6, \mathrm{red}\right)$ and paranodes (CASPR, green; Figure 3F-G) within the fimbria of no-learning 
and learning mice. Unlike iTBS, which shortened nodes, spatial learning produced a shift in node length distribution towards longer nodes (Figure 3H) and produced a corresponding $\sim 16 \%$ increase in average node length (Figure 3I). However, like iTBS, spatial learning did not alter the average length or length distribution of paranodes (Figure S3D-E). These data indicate that the nodes of Ranvier are dynamic and can lengthen or shorten in response to altered neuronal activity. Furthermore, these changes in node length occur without changing paranode length.

\section{Mature nodes of Ranvier are plastic}

Oligodendrogenesis is driven by neuronal activity [reviewed by (Pepper et al., 2018)] and can influence node length (Schneider et al., 2016), making it possible that activity-induced nodal plasticity is a consequence of increased oligodendrocyte addition. However, this seems unlikely as oligodendrogenesis would be expected to consistently shorten nodes in the cortex and fimbria, and iTBS does not enhance oligodendrocyte addition to the $\mathrm{CC}$ (Cullen et al., 2019). To determine whether nodal plasticity can occur in the absence of oligodendrogenesis, tamoxifen was administered to P76 Pdgfro-CreER ${ }^{T M}::$ Rosa26-YFP :: Myrfl/fl (Myrf-deleted) mice, to fluorescently label OPCs and conditionally delete myelin regulatory factor (Myrf), a transcription factor essential for myelination and myelin maintenance (Emery et al., 2009). The conditional deletion of Myrf from adult OPCs reduced oligodendrocyte addition in M1 $(\mathrm{p}<0.05)$ and the $\mathrm{CC}(\mathrm{p}<0.001)$ by $>60 \%$ within 30 days of tamoxifen delivery (Figure S4AF). When sham-stimulation or iTBS was initiated 14 days after Tx $(\mathrm{P} 76+14)$, and the nodes of Ranvier $\left(\mathrm{Na}_{\mathrm{v}} 1.6\right)$ imaged in the M1 at P76+28 (Figure S4G-H), iTBS again shifted the node length distribution towards shorter nodes (Figure S4I; K-S test, $\mathrm{p}<0.0001$ ), and decreased average node length by $\sim 16 \%$ (Figure S4J; t-test $\mathrm{p}=0.04$ ). Within the CC of Myrf-deleted mice, iTBS also shortened nodes (Figure S4K; K-S test, $\mathrm{p}<0.0001$; Figure S4L; t-test, $p=0.01$ ), 
indicating that node shortening in response to iTBS cannot be entirely attributed to new oligodendrocyte addition.

To explore the possibility that nodal plasticity is instead mediated by mature, pre-existing oligodendrocytes, we selectively measured the length of already mature nodes of Ranvier $\left(\mathrm{Na}_{\mathrm{v}} 1.6\right)$ following iTBS or sham-stimulation in Plp-CreER :: Tau-mGFP transgenic mice. These nodes were flanked by $\mathrm{mGFP}^{+}$pre-existing internodes and formed prior to treatment (Figure 4A-B). Within M1, iTBS shortened the mature nodes (Figure 4C) and tended to decrease the average length of mature nodes in each mouse by $\sim 18 \%$ (Figure $4 D, p=0.056$ ). Within the CC, iTBS also shifted mature node length distribution towards shorter nodes (Figure 4E), corresponding to a $\sim 23 \%$ decrease in average node length (Figure 4F), and suggesting that node shortening is facilitated by mature oligodendrocytes.

To determine whether node lengthening induced by spatial learning is also facilitated by mature oligodendrocytes, we similarly analysed nodes $\left(\mathrm{Na}_{v} 1.6\right)$ that were flanked by $\mathrm{mGFP}^{+}$preexisting internodes in the fimbria of no-learning (Figure 4G) and learning (Figure 4H) PlpCreER :: Tau-mGFP transgenic mice. Consistent with our earlier observations, learning shifted mature node length distribution towards longer nodes (Figure 4I), which corresponded to an increase in the average length of mature nodes in each mouse of $\sim 17 \%$ (Figure $\mathbf{4 J}$; $\mathrm{p}=0.051$ ). These data suggest that mature oligodendrocytes can facilitate bi-directional, activity-induced nodal plasticity through the subtle expansion or retraction of existing myelin internodes.

iTBS and spatial learning alter the size of the periaxonal space

For internodes to encroach on or retract from the nodes of Ranvier, the thickness or structure of myelin may be modified. For example, the sustained activation of extracellular signalregulated kinases 1 and $2(E R K 1 / 2)$ in mature oligodendrocytes induces a marked decrease in 
node length in the CC of adult mice by increasing myelin thickness (Jeffries et al., 2016) and in the optic nerve, the thrombin-dependent detachment of paranodal loops led to thinner myelin (fewer myelin wraps) and longer nodes of Ranvier (Dutta et al., 2018). Therefore, we performed transmission electron microscopy (TEM) to quantify the g-ratio [axon diameter / (axon + myelin sheath diameter)] of myelinated axons in the CC of adult sham and iTBS treated mice (Figure 5A-K). We found that the distribution of g-ratios was left-shifted, indicating that iTBS treatment reduced axon g-ratio (Figure 5A-B), and this corresponded to a reduction of $\sim 7 \%$ in the average g-ratio of myelinated axons in iTBS mice compared with controls (Figure 5C).

As axon diameter was equivalent between treatment groups (iTBS: $0.53 \pm 0.17 \mu \mathrm{m}$; sham: 0.58 $\pm 0.16 \mu \mathrm{m}$, t-test $\mathrm{p}=0.09)$, the decreased g-ratio could reflect an increase in myelin thickness; however, when we quantified the number of myelin wraps around individual axons in the $\mathrm{CC}$, by counting the major dense lines within each myelin sheath, we found that the number of myelin wraps was not affected by treatment (Figure 5D-I). Similarly, the average thickness of each wrap [the distance between each major dense line; capped lines in Figure 5E, G; sham: $8.3 \pm 0.3 \mathrm{~nm}$, iTBS: $8.6 \pm 0.2 \mathrm{~nm}$, mean $\pm \mathrm{SD}, \mathrm{n}=3$ per group, $\mathrm{t}$-test, $\mathrm{t}=1.27, \mathrm{p}=0.27]$ and the width of the inner tongue process (sham: $30 \pm 7 \mathrm{~nm}$; iTBS: $31.6 \pm 3.2 \mathrm{~nm}$, mean $\pm \mathrm{SD}, \mathrm{n}=3$ per group, $\mathrm{t}$-test, $\mathrm{t}=0.35, \mathrm{p}=0.73$ ) were unchanged by iTBS treatment. Surprisingly, the width of the fluid-filled space under the internode, between the axon and the myelin sheath, known as the periaxonal space increased by $\sim 47 \%$ following iTBS (Figure $\mathbf{5 J - K}$ ), perhaps suggesting that the myelin sheath is pushed outwards or reconfigured away from the axon.

Remarkably, spatial learning had the opposite effect on myelin ultrastructure in the fimbria (Figure 5L-T). Learning produced a significant leftward-shift in the g-ratio distribution for myelinated axons in the fimbria (Figure 5L-M), corresponding to a $\sim 9 \%$ increase in the 
average g-ratio (Figure $\mathbf{5 N}, \mathrm{p}=0.057$ ). This increase in g-ratio could not be explained by a change in axon diameter (no-learning: $0.61 \pm 0.01 \mu \mathrm{m}$, learning: $0.56 \pm 0.11 \mu \mathrm{m}$, mean $\pm \mathrm{SD}$; $\mathrm{n}=3$ per group, $\mathrm{t}$-test, $\mathrm{t}=0.87, \mathrm{p}=0.42$ ) or the number of myelin wraps elaborated (Figure 50R), but was associated with a $\sim 29 \%$ decrease in the average width of the periaxonal space (Figure 5S-T). These data suggest that bidirectional mechanisms link changes in neuronal activity with adaptive changes in myelin ultrastructure: iTBS is associated with an expansion of the periaxonal space and a contraction of the nodes of Ranvier for axons in the CC, while spatial learning is associated with a contraction of the periaxonal space and an extension of the nodes of Ranvier for axons in the fimbria.

The size of the periaxonal space modulates conduction velocity

The frequency and composition of nodal domains can have a marked impact on action potential propagation along an axon (Ford et al., 2015; Freeman et al., 2016; Schneider et al., 2016), and node length is predicted to exert a strong influence on action potential conduction speed (Arancibia- Carcamo et al., 2017; Ford et al., 2015; Halter and Clark, 1993). Within the cortex, the estimated density of $\mathrm{Na}_{\mathrm{v}} 1.6$ channels at the node is directly proportional to node length, and this constant density of ion channels is predicted to induce a concave relationship between node length and speed of conduction, with very short or very long nodes causing a reduction in conduction velocity along axons (Arancibia- Carcamo et al., 2017). Furthermore, the inclusion or omission of a periaxonal space predicts whether new internodes, added to the mature brain, increase or decrease the simulated conduction velocity of an axon, respectively (Young et al., 2013). More recently, it was shown that electrical conductance within the periaxonal space facilitates the saltatory propagation of action potentials and that increasing the size of this space would theoretically slow conduction velocity (Cohen et al., 2020). 
To determine how changes in node length and periaxonal ultrastructure might influence conduction speed, we performed computational simulations of action potential propagation in myelinated callosal axons by further adapting the mathematical model developed by Richardson and colleagues (Bakiri et al., 2011; Richardson et al., 2000) (Figure 6A-B; see STAR methods and Figure S5). Using this model, we initially explored how the size of the periaxonal space might impact conduction velocity (Figure 6C-D). In line with Cohen et al. (2020), we find that simulated conduction velocity is up to 3.5 times slower when the periaxonal space width is set to $20 \mathrm{~nm}$ rather than $0 \mathrm{~nm}$ (Figure 6C), which equates to a conduction delay of up to $\sim 9 \mathrm{~ms}$ (at $21^{\circ} \mathrm{C}$ ) over a distance of $1 \mathrm{~cm}$ (Figure 6D).

By initially configuring the model parameters so that the periaxonal space was uniform under the internode and paranode (Figure 6E), and setting all other parameters to match those measured under sham conditions (Figure 6F; Table S1), we obtained a theoretical conduction velocity of $1.18 \mathrm{~m} / \mathrm{s}$ at $21^{\circ} \mathrm{C}\left(1.91 \mathrm{~m} / \mathrm{s}\right.$ at $37^{\circ} \mathrm{C}$; Figure S5). Reducing the node length, as occurred during iTBS (Figure 2; Table S1), slowed action potential propagation by $\sim 2.3 \%$, while altering the myelin sheath parameters (decreased g-ratio + increased periaxonal space; Figure 5; Table S1) exerted a greater influence on conduction speed, effectively slowing propagation by $\sim 8.6 \%$ (Figure $6 \mathbf{F}$ ). Implementing all of the ultrastructural changes observed following iTBS (reduced node length and g-ratio + increased periaxonal space; Figure 2, Figure 5, Table S1) had an additive effect, slowing conduction velocity by $\sim 10.9 \%$ (to $1.05 \mathrm{~m} / \mathrm{s}$; Figure $6 \mathbf{F})$. This effect was exaggerated at $37^{\circ} \mathrm{C}$ with iTBS inducing a theoretical $\sim 12.3 \%$ reduction in conduction speed (Figure S5D).

We then changed the model parameters so that the periaxonal space under the internode could change, while the periaxonal space at the paranode did not exceed 3nm (Figure 6G), which is the middle of the size range that has been reported elsewhere (Nans et al., 2011; Rosenbluth, 1995; Waxman et al., 1995). In this scenario, the simulated conduction velocity for sham- 
stimulated axons was slightly faster, being $1.34 \mathrm{~m} / \mathrm{s}$ at $21^{\circ} \mathrm{C}\left(\right.$ Figure $6 \mathbf{H} ; 37^{\circ} \mathrm{C}$ data shown in Figure S5F). Reducing node length still slowed conduction velocity by $\sim 2.3 \%$, but the effect of altering the myelin sheath parameters was diminished, slowing conduction by only $\sim 3.7 \%$ and the combined effect of reduced node length + altered myelin (iTBS) was also weaker, inducing a theoretical $\sim 6 \%$ reduction in conduction speed (Figure $6 \mathbf{H}$ ) which was similar at $37^{\circ} \mathrm{C}(\sim 5.7 \%$ reduction, Figure $\mathbf{S 5 F})$. In a third model, we set the periaxonal space width at the paranode to be half of the width of the periaxonal space under the internode, creating a scenario in which the periaxonal space is narrower at the paranode, but changes proportionally with the internodal periaxonal space (Figure 6I). In this scenario, the simulated conduction velocity using sham parameters was $1.32 \mathrm{~m} / \mathrm{s}$ (Figure 6J) at $21^{\circ} \mathrm{C}\left(37^{\circ} \mathrm{C}\right.$ data shown in Figure S5H), but the reduction in conduction velocity induced by altering myelin sheath parameters $(\sim 9.2 \%)$ or by mimicking the iTBS condition $\left(\sim 11.5 \%\right.$, Figure $6 \mathbf{J} ; 12.5 \%$ at $37^{\circ} \mathrm{C}$, Figure S5H) was comparable to the case where periaxonal space width was homogenous along the internode and paranode (Figure 6E-F).

Finally, we modelled action potential conduction in the fimbria using a parameter set matching the experimental observations obtained in the no-learning condition (Figure 6K-L; Table S1). The simulated conduction velocity along fimbria axons in the no-learning (NL) condition was $0.95 \mathrm{~m} / \mathrm{s}$ (Figure 6L) at $21^{\circ} \mathrm{C}\left(37^{\circ} \mathrm{C}\right.$ data shown in Figure $\left.\mathbf{S 5 L}\right)$, which is far slower than the simulated velocity in the $\mathrm{CC}$, but is within range of measured conduction velocities for this region (Corcoba et al., 2015; Jones et al., 1999). Increasing the node length by $30 \%$, to reflect the change produced by RAM learning (Figure 3), increased the simulated conduction speed by $8.9 \%$, while altering the myelin sheath parameters (increased g-ratio + decreased periaxonal space, Figure 5, Table S1) increased conduction velocity by 7.3\%. Again, implementing all of the changes measured following learning (L; increased node length and g-ratio + decreased periaxonal space; Figure 3, Figure 5, Table S1) had an additive effect, increasing conduction 
velocity by $16.6 \%$ (Figure $6 \mathrm{~L}$ ). At $37^{\circ} \mathrm{C}$, this would be predicted to correspond to a $21.6 \%$ increase in conduction velocity following learning (Figure S5L). These data suggest that adaptive structural changes at nodes of Ranvier and the periaxonal space act in concert to slow down or speed up action potential conduction along an axon.

iTBS slows conduction velocity across the CC

As our model predicted that iTBS would, on average, decrease action potential conduction velocity along axons in the $\mathrm{CC}$, we decided to measure this by performing ex vivo field potential recordings of compound action potentials (CAPs) in the CC of sham and iTBS mice (Figure 7A). We found that the average conduction velocity along myelinated (M) CC axons in sham stimulated mice was $1.27 \pm 0.19 \mathrm{~m} / \mathrm{s}$ (Figure 7B), which is remarkably similar to the speed predicted by our simulations (Figure 6J). Conduction velocity along myelinated axons was reduced by $\sim 18 \%$ following iTBS $(1.04 \pm 0.19 \mathrm{~m} / \mathrm{s}$; Figure $7 \mathbf{B})$. The amplitude of the myelinated axon component of the CAP also increased by $40 \%$ following iTBS (Figure 7C), and the half-width decreased by $\sim 9 \%$ (Figure 7D), suggesting that a greater number of action potentials arrived simultaneously at the recording electrode. The unmyelinated axon (UM) component of the CAP was not altered by iTBS treatment (Figure 7A-D). These data validate our in silico predictions and suggest that oligodendrocytes can make subtle changes to their myelin ultrastructure that impact the length of nodes of Ranvier and the size of the periaxonal space, and this allows them to fine-tune conduction velocity and enhance the coordinated conduction of action potentials within the active circuit.

\section{Discussion:}

Are mature oligodendrocytes adaptable? 
In recent years, it has become increasingly evident that central myelination is adaptive [see (Almeida and Lyons, 2017; Bechler et al., 2017; Mount and Monje, 2017) for reviews] and that changing the pattern of myelination within a circuit could have a profound impact on neural processing (Pajevic et al., 2014). This area of research has largely focussed on the addition of new myelin over time and in response to altered neuronal activity (Cullen et al., 2019; Gibson et al., 2014; Li et al., 2010; McKenzie et al., 2014; Mitew et al., 2018; Sampaio-Baptista et al., 2013; Xiao et al., 2016; Young et al., 2013), but we do not yet know whether existing oligodendrocytes adapt to altered neuronal activity and whether this affects the propagation of action potentials. Using a combination of fluorescence microscopy, ultrastructural analysis, computational modelling and electrophysiological recordings, we now show that the nodes of Ranvier and the periaxonal space undergo bi-directional plasticity in response to the artificial or physiological modulation of neuronal activity and that this response is likely mediated by mature oligodendrocytes. Furthermore, these adaptive changes in axo-myelin ultrastructure synergistically fine-tune conduction velocity along myelinated axons within the active circuit.

Once formed, mature myelinating oligodendrocytes are long lived (Tripathi et al., 2017) and the majority of the internodes they support are stable over time, however, there is some evidence that these mature cells retain the capacity to adjust internode length if required (Auer et al., 2018; Hill et al., 2018). We sought to determine whether changes in neural circuit activity could trigger adaptive changes in mature internodes but found that neither iTBS or spatial learning induced an overt extension or retraction of mature internodes (Figures $\mathbf{1} \& \mathbf{3}$ ). These data are consistent with fluorescent live imaging data showing that existing myelin sheaths within the somatosensory cortex do not change length in response to sensory enrichment or deprivation (Hughes et al., 2018). However, we observed marked alterations in the length of the nodes of Ranvier following both iTBS and spatial learning. Low intensity iTBS reduced node length within M1 and the underlying CC (Figures 2, 4, S2 \& S4), while 
spatial learning increased node length within the hippocampal fimbria (Figures $3 \&$ 4). These dynamic changes appear to be mediated by subtle adaptations made by mature oligodendrocytes, as preventing new oligodendrocyte addition did not impact iTBS-induced node shortening (Figure S4), and both iTBS and learning could alter the length of nodes that were already mature (flanked by pre-existing myelin internodes) prior to the change in activity (Figure 4). Previous studies have reported pathological node lengthening (Hinman et al., 2015; Howell et al., 2006; O'Hare Doig et al., 2017; Reimer et al., 2011) associated with myelin loss (Howell et al., 2006) or paranodal pathology (Huff et al., 2011; Reimer et al., 2011), however, we found no evidence of myelin pathology following iTBS or learning, which is a natural, physiological stimuli. Others have suggested that node length may be plastic and physiologically modulated (Arancibia-Carcamo et al., 2017; Ford et al., 2015) but, to our knowledge, this is the first experimental evidence of activity-induced adaptive plasticity at the node of Ranvier in vivo.

\section{Plasticity of the periaxonal space}

iTBS decreased the g-ratio of myelinated axons in the CC. This is consistent with various other forms of cortical activity modulation, including the direct optogenetic stimulation of layer $\mathrm{V}$ pyramidal neurons in the premotor cortex (Gibson et al., 2014), the pharmacogenetic stimulation of layer $2 / 3$ pyramidal neurons in the primary somatosensory cortex (Mitew et al., 2018) and the optogenetic inhibition of parvalbumin ${ }^{+}$interneurons in the anterior cingulate cortex (Piscopo et al., 2018), that similarly decreased the g-ratio of axons within the underlying CC. However, we found that the decrease in g-ratio observed following iTBS was not the result of increased myelin thickness, or decreased axon diameter, but was instead associated with a marked increase in the periaxonal space (Figure 5). Surprisingly, spatial learning instead increased the g-ratio of myelinated axons within the hippocampal fimbria and was this 
was associated with a decrease in the size of the periaxonal space (Figure 5). This is the first report of an ultrastructural adaptation of the periaxonal space in response to altered neuronal activity. However, the periaxonal space has been reported to undergo pathological changes. For example, the periaxonal space is diminished in mice deficient in myelin associated glycoprotein (MAG) (Georgiou et al., 2004; Li et al., 1994; Quarles, 2007) - a protein expressed specifically in the periaxonal myelin membrane (Pronker et al., 2016), and vacuoles form within this space along optic nerve axons following connexin $32 / 47$ knock-out (Menichella et al., 2006). Marked pathological swelling of the periaxonal space has also been observed following acute ischemic white matter injury and demyelination (Aboul-Enein et al., 2003). However, vacuolisation, or an uneven separation of the myelin from the axons was not observed in our tissue, suggesting that iTBS- or learning-induced modulation of the periaxonal space is not pathological, but a physiological adaptation to altered neuronal activity.

\section{Nodal and periaxonal plasticity modulate action potential conduction}

The periaxonal space has been hypothesised to act as a receptacle for calcium, glutamate and potassium released by the axon during action potential propagation, as well as oligodendrocyte derived lactate and pyruvate, which is then shuttled through monocarboxylate transporters to provide metabolic support to the axon [reviewed in (Micu et al., 2017)], and as an important regulatory element of action potential conduction. The inclusion or omission of a periaxonal space predicts whether the addition of new internodes to an axon increased or decreased simulated conduction velocity along that axon (Young et al., 2013) and experimentallyconstrained cable modelling revealed that the periaxonal space is almost certainly conductive and that current flow through this fluid filled space helps facilitate the saltatory propagation of action potentials along myelinated axons (Cohen et al., 2020). In line with our own data 
(Figure 6), these authors also show a marked theoretical slowing of conduction speed as the width of the periaxonal space is increased (Cohen et al., 2020).

Previous ultrastructural analyses of myelinated axons in the CNS have shown that the periaxonal space is typically narrower at the paranode than under the internode (Nans et al., 2011; Rosenbluth, 1995; Waxman et al., 1995) and the capacity for ultrastructural adaptation of the periaxonal space to influence axonal conduction speed is likely to be dependent on its size both under the internode, and at the paranode. As we were unable to measure periaxonal space width at the paranode, we instead modelled action potential propagation along callosal axons following sham or iTBS treatment, incorporating three possible paranodal scenarios: i) that the periaxonal space width was uniform under the internode and paranode and changed proportionally; ii) that the periaxonal space under the paranode was narrower than under the internode and did not exceed $3 \mathrm{~nm}$; and iii) that the periaxonal space is narrower at the paranode, but changes proportionally with the internodal periaxonal space (Figure 6, S5). While narrowing the periaxonal space at the paranode increased predicted conduction velocities compared to a theoretically uniform periaxonal space width, in each of these scenarios adjusting the node length and the internodal periaxonal space width to match the experimental values obtained following iTBS consistently slowed the simulated conduction speeds compared to the sham condition (Figure 6, S5), though the effect was not as strong when the paranodal periaxonal space width remained constant.

When we performed computation modelling to assess the impact that each ultrastructural adaptation measured could have on conduction velocity, we found that the iTBS-induced decrease in node length was predicted to slow conduction velocity, while the learning induced increase in node length was predicted to increase conduction velocity (Figure 6; S5). These data are consistent with the theoretical inverse $U$ relationship between conduction speed and 
node length in cortical axons, when sodium channel density at the node of Ranvier remains constant (Arancibia-Carcamo et al., 2017). These earlier predictions indicate that at an average internode length of either $\sim 50 \mu \mathrm{m}$ (as per our CC data), or $\sim 37 \mu \mathrm{m}$ (as per our fimbria data), conduction velocity would be faster when node lengths were set to $1.5 \mu \mathrm{m}$ compared to $0.5 \mu \mathrm{m}$, though further increasing node length to $3.5 \mu \mathrm{m}$ was predicted to markedly slow conduction speed when internode lengths were shorter than $\sim 50 \mu \mathrm{m}$ (Arancibia-Carcamo et al., 2017). In the context of iTBS, our computational modelling suggests that expanding the periaxonal space has a larger effect on action potential slowing than shortening the node length; however, following spatial learning, increasing node length and decreasing the width of the periaxonal space sped up action potential conduction to a similar extent. In both cases, altering node length and periaxonal space width had a synergistic effect, working together to slow or speed action potential conduction in the iTBS and learning simulations, respectively. These data are the first to demonstrate a synergistic relationship between node length and periaxonal space width in regulating the speed of action potential conduction along myelinated axons.

\section{Regulating conduction velocity is important for neural network function}

It is likely that the dynamic modulation of action potential conduction velocity could be an adaptive mechanism to ensure the coincident arrival of action potentials at post-synaptic targets, and a mechanism that will allow circuits to adapt to the altered stimulation of specific circuits. Indeed, when we performed ex vivo CAP recordings in the CC of iTBS or sham stimulated mice we found that iTBS not only slowed CAP conduction along these axons, as our simulations predicted, but that the peak amplitude of the CAP response was increased and the half-width decreased, indicating a more synchronised arrival of action potentials at the recording electrode (Figure 7). At the network level, adjusting signal arrival at post-synaptic 
neurons could also affect the balance of excitation and inhibition, effectively altering their probability of firing, and may also determine whether potentiation or depression is induced (Feldman, 2012; Markram et al., 2012). The precise regulation of action potential conduction velocity and the firing frequency of neuronal populations is also important for synchronous or time-locked brain wave oscillations (Pajevic et al., 2014), which are associated with various cognitive functions including selective attention, information processing, sensory gating of information, learning, memory formation and consciousness (Ainsworth et al., 2012; Burgess et al., 2007; Buzsaki, 2006; Sirota et al., 2008). We propose that the combined plasticity of the periaxonal space and the nodes of Ranvier is a vital homeostatic mechanism for refining action potential conduction in response to altered neural circuit activity.

Acknowledgments: We thank our colleagues at the University of Tasmania and Rowan Tweedale (Queensland Brain Institute, the University of Queensland) for constructive feedback on the manuscript and suggestions for improvement. We also thank Dr Lee Cossell and Prof David Atwell (University College London) for their advice on computational modelling, as well as Dr Carola Thoni and Mr Shane Rix (Lastek: Photonics Technology Solutions, Australia) for their assistance with STED imaging. Funding: This research was supported by grants from the National Health and Medical Research Council of Australia (NHMRC; 1077792, 1139041), MS Research Australia (11-014, 16-105; 17-007), the Australian Research Council (DP180101494), the Swiss National Science Foundation (31003A_170079) and the National MS Society. CLC was supported by a fellowship from MS Research Australia and the Penn Foundation (15-054). KAP was supported by a fellowship from the NHMRC (1139180). LA was supported by an Australian Postgraduate Award. MTC and RP were supported by scholarships from the Menzies Institute for Medical Research, University of Tasmania. BE was supported a fellowship from the NHMRC (1032833) and a Warren endowed professorship in neuroscience research. KMY was supported by fellowships from the NHMRC (1045240) and MS Research Australia / the Macquarie Group Foundation (170223). JR was supported by fellowships from the NHMRC (1002258) and the Perron Institute for Neurological and Translational Science and MS Western Australia. 
Author contributions: CLC, KMY, RBJ, REP, KAP, JR and BE developed the project and wrote the manuscript. CLC, REP, KAP, MTC, LA, VO, RBJ and KMY carried out the experiments. KMY, JR, CLC, BE and RBJ obtained the funding. CLC, REP, MTC and RBJ performed the statistical analyses and generated the figures. KMY, ADT, GR, JR and CLC provided supervision.

Competing interests: Authors declare no competing interests. 


\section{Figures:}

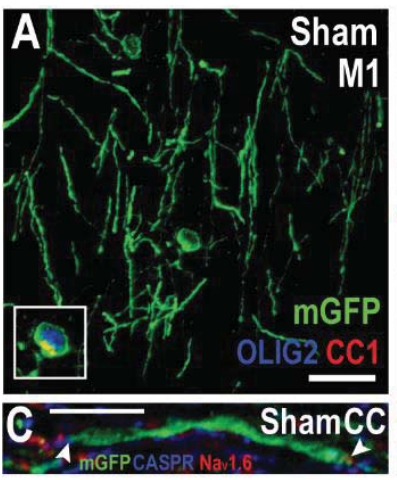

E

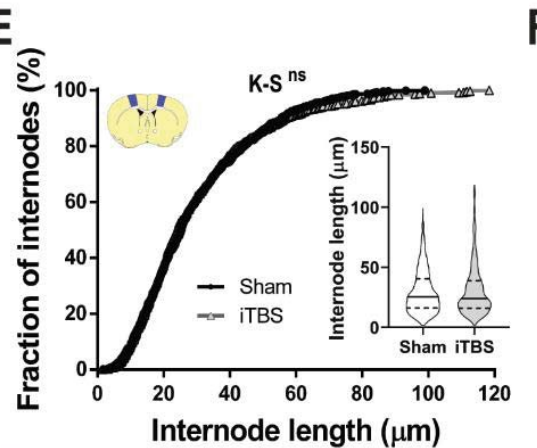

G

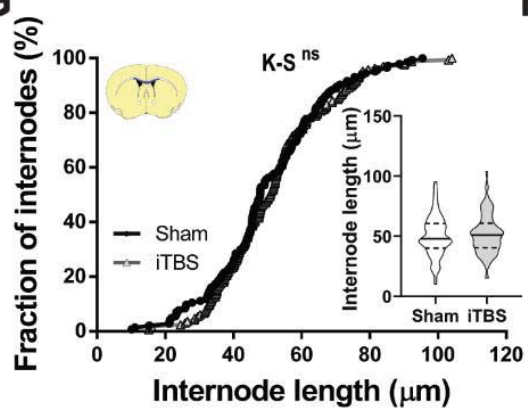

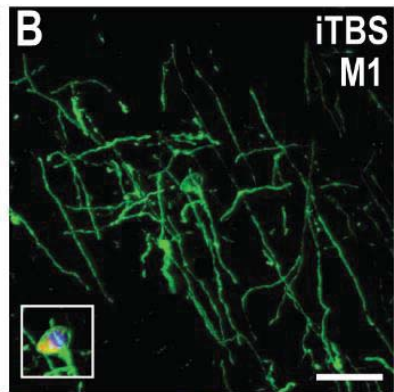

iTBSCC

$\mathbf{F}$

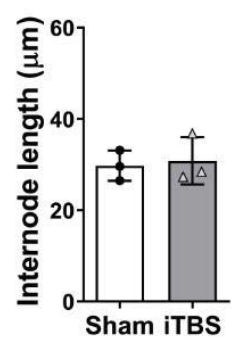

$\mathrm{H}$

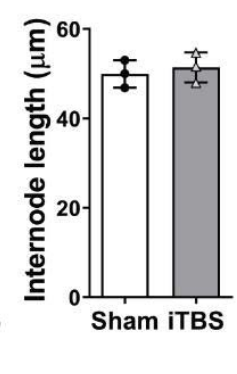

Figure 1. iTBS does not alter oligodendrocyte gross myelinating morphology

A-B) Representative compressed confocal z-stack of a $\mathrm{mGFP}^{+}$(green) oligodendrocyte in the primary motor cortex (M1) of Plp-CreER::Tau-mGFP transgenic mice after 14 days of shamstimulation (A) or iTBS (B). Inset, $\mathrm{mGFP}^{+}$cell bodies show co-labeling for $\mathrm{CC} 1$ (red) and OLIG2 (blue). C-D) single $\mathrm{mGFP}^{+}$internodes flanked on either end by CASPR ${ }^{+}$paranodes (blue) and dense $\mathrm{Na}_{\mathrm{v}} 1.6$ staining at the node of Ranvier (red) in the corpus callosum (CC) of sham-stimulated (C) or iTBS (D) mice. E-F) Cumulative internode length distribution for $\mathrm{mGFP}^{+}$internodes measured within M1 of sham (black circles) and iTBS (gray triangles) treated mice (E) [744 sham and 733 iTBS internodes; K-S test, K-S D=0.049, p=0.32; inset violin plot of internode length, Mann Whitney $\mathrm{U}(\mathrm{MWU})$ test $\mathrm{p}=0.63$ ] and the average M1 internode length per animal (F) in sham (white bars) and iTBS (gray bars) treated mice $[\mathrm{n}=3$ mice per group, t-test, $\mathrm{t}=0.31, \mathrm{p}=0.77]$. G-H) Cumulative internode length distribution for mGFP $^{+}$internodes measured within CC $(\mathbf{G})$ [n=144 sham and $\mathrm{n}=166$ iTBS internodes; K-S test, K-S D $=0.08, p=0.63$; inset violin plot of internode length, MWU test $p=0.57$ ] the average $\mathrm{CC}$ internode length per animal $(\mathbf{F})$ sham and iTBS treated mice $[\mathrm{n}=3$ mice per group, $\mathrm{t}$-test, $\mathrm{t}=0.55, \mathrm{p}=0.61]$. Arrowheads indicate the end of an internode. Violin plots show the median (solid line) and interquartile range (dashed lines). Bars show mean \pm SD. Scale bars represent $20 \mu \mathrm{m}$. 

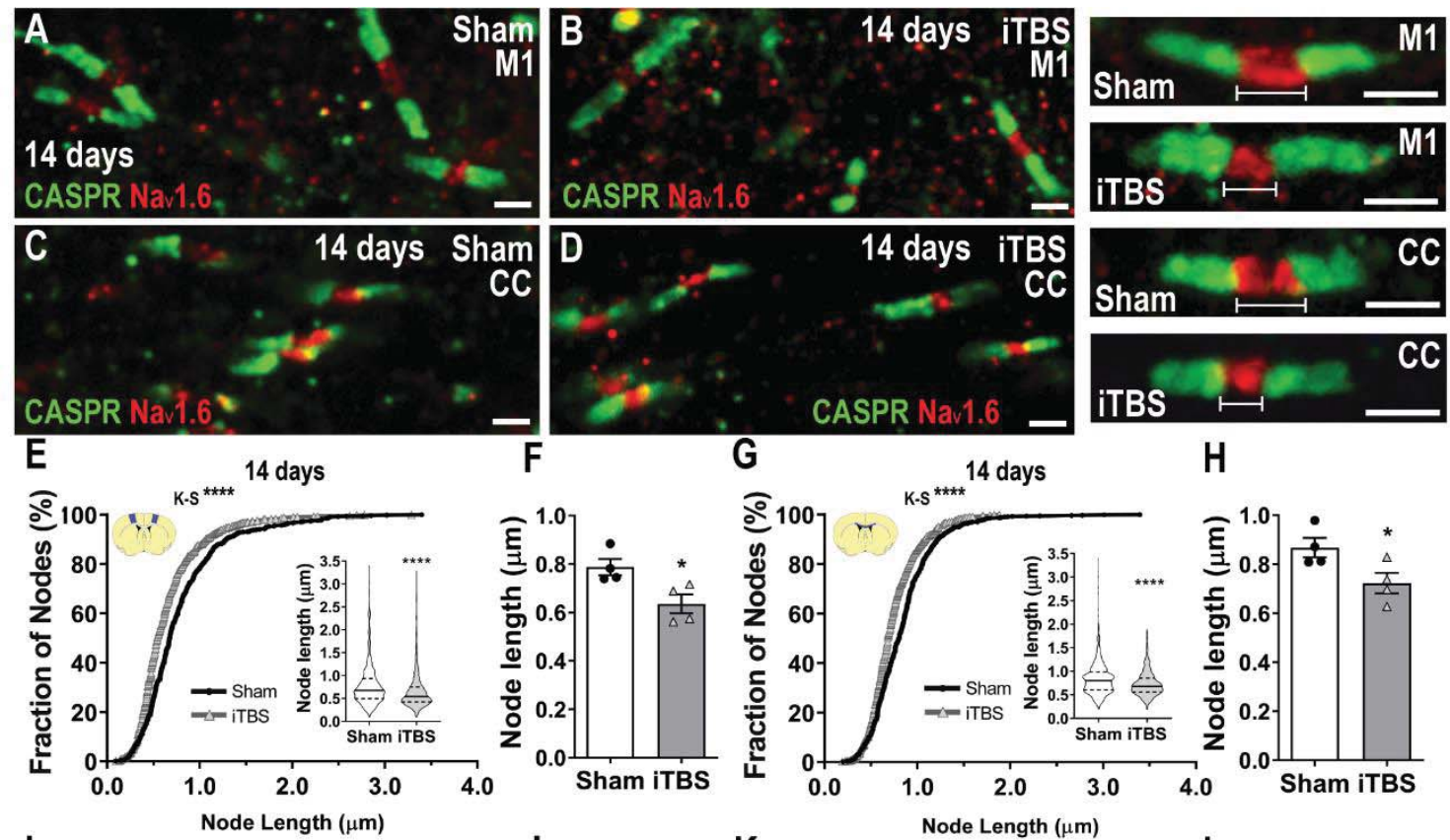

$\mathrm{H}$
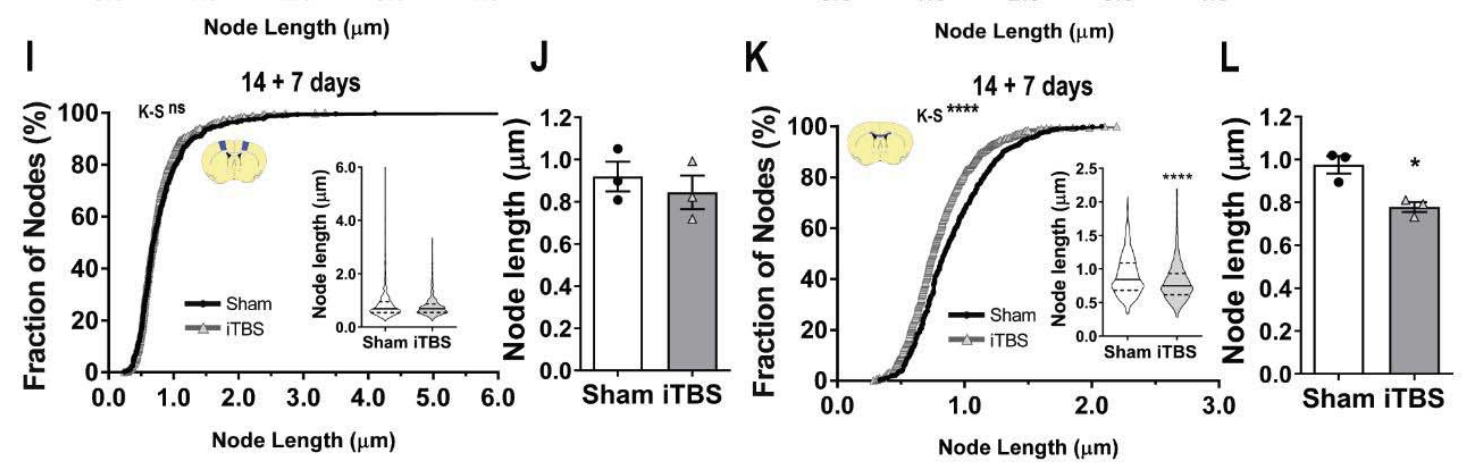

Figure 2. iTBS shortens nodes of Ranvier.

A-D) Confocal images of nodes of Ranvier $\left(\mathrm{Na}_{\mathrm{v}} 1.6\right.$; red) and paranodes (CASPR; green) in M1 (A, B) and the CC (C, D) after 14 days of sham-stimulation or iTBS. E-F) Cumulative node length distribution in M1 [656 sham (black circles) and 802 iTBS (gray triangles) nodes; Kolmogorov-Smirnov (K-S) test, K-S $\mathrm{D}=0.19, \mathrm{p}<0.0001$; inset, violin plot of node length, Mann Whitney U (MWU) test, $\mathrm{p}<0.0001]$ and average M1 node length per animal $(\mathbf{F})$ in sham (white bars) and iTBS treated (gray bars) mice [ $\mathrm{n}=4$ mice per group, $\mathrm{t}$-test, $\mathrm{t}=2.95, \mathrm{p}=0.02]$. GH) Cumulative node length distribution in CC (G) [867 sham and 700 iTBS nodes; K-S $\mathrm{D}=0.13, \mathrm{p}<0.0001$; inset, violin plot of node length, MWU test, $\mathrm{p}<0.0001$ ] and average $\mathrm{CC}$ node length per animal $(\mathbf{H})$ in sham (white bars) or iTBS (gray bars) mice $[\mathrm{n}=4$ mice per group, $\mathrm{t}$-test, $\mathrm{t}=2.50, \mathrm{p}=0.04]$. I-J) Cumulative node length distribution in M1 (I) [452 sham and 576 iTBS nodes; K-S D=0.070, $p=0.15$; inset, violin plot of node length, MWU test, $p=0.35$ ] and average M1 node length per animal ( $\mathbf{J})$ in sham and iTBS treated mice $[\mathrm{n}=3$ per group, $\mathrm{t}$-test, $\mathrm{t}=0.70, \mathrm{p}=0.52] 7$ days after cessation of stimulation $(14+7$ days $) . \mathbf{K}-\mathbf{L})$ Cumulative node length distribution in $\mathrm{CC}(\mathbf{K})$ [587 sham and 696 iTBS nodes; $\mathrm{K}-\mathrm{S} \mathrm{D}=0.16, \mathrm{p}<0.0001$; inset, violin plot of node length, MWU test, $\mathrm{p}<0.0001]$ and average $\mathrm{CC}$ node length per animal (L) in sham and iTBS treated mice [ $\mathrm{n}=3$ per group, t-test, $\mathrm{t}=4.2, \mathrm{p}=0.01] . * \mathrm{p}<0.05, * * * *<<0.0001$. Violin plots show the median (solid line) and interquartile range (dashed lines). Bars show mean \pm SD. Scale bars represent $1 \mu \mathrm{m}$. 

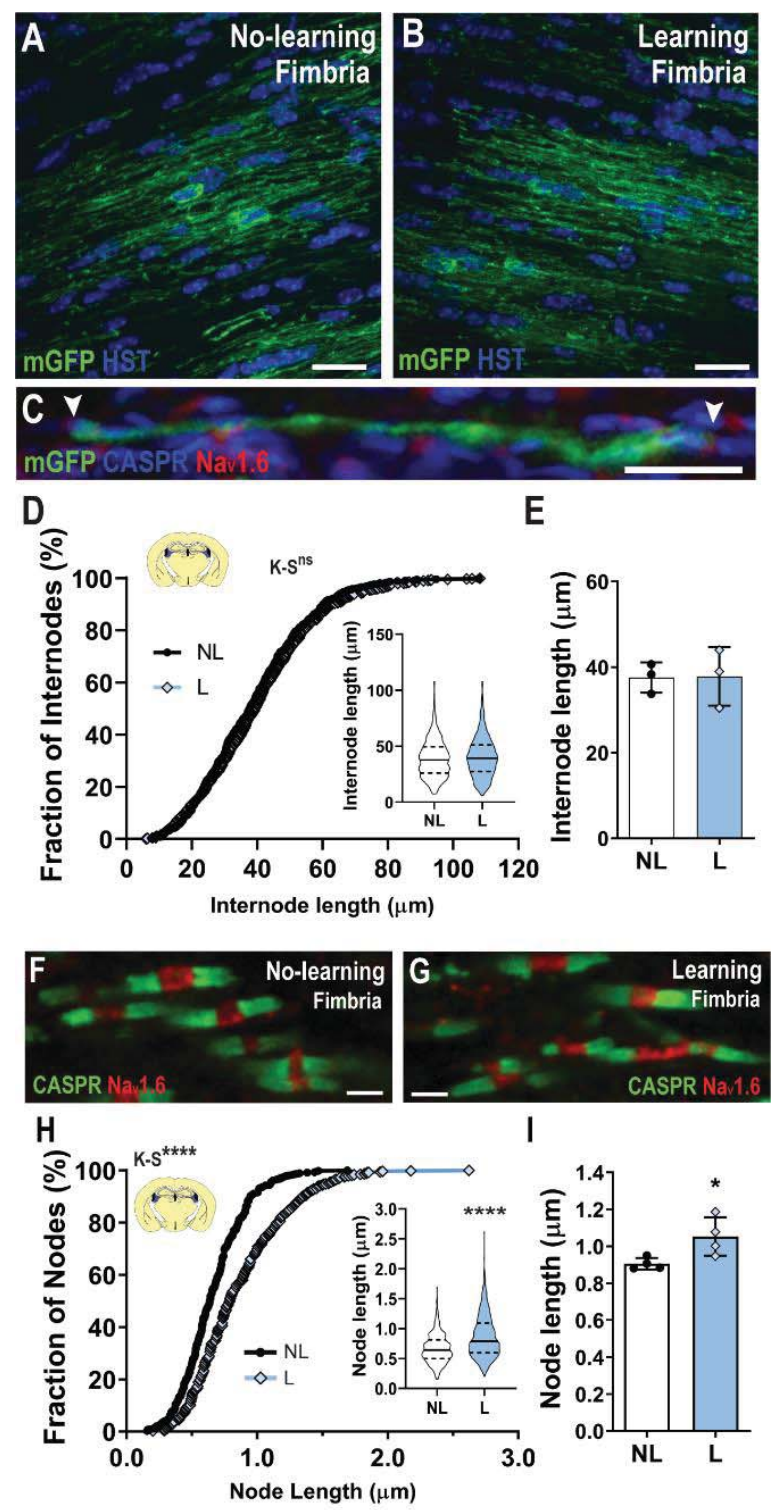

Figure 3. Spatial learning lengthens nodes of Ranvier.

A-B) Representative compressed confocal z-stack of a $\mathrm{mGFP}^{+}$(green) oligodendrocytes in the primary motor cortex (M1) of Plp-CreER::Tau-mGFP transgenic mice after 14 days of nolearning (A) or learning (B) in the radial arm maze. C) example of a single $\mathrm{mGFP}^{+}$internode flanked on either end by CASPR ${ }^{+}$paranodes (blue) and dense $\mathrm{Na}_{\mathrm{v}} 1.6$ staining (red) at the node of Ranvier. D-E) Cumulative internode length distribution for $\mathrm{mGFP}^{+}$internodes measured within the fimbria of no-learning (NL; black circles) and learning (L; blue diamonds) mice (D) $[\mathrm{n}=532 \mathrm{NL}$ and $\mathrm{n}=685 \mathrm{~L}$; K-S test, K-S D=0.054, $\mathrm{p}=0.34$; inset violin plot of internode length, Mann Whitney $U$ (MWU) test $p=0.15]$ and the average fimbria internode length per animal (E) in NL (white bars) and L (blue bars) mice [ $\mathrm{n}=3$ mice per group, $\mathrm{t}$-test, $\mathrm{t}=0.053, \mathrm{p}=0.96]$. F-G) representative confocal images of nodes of Ranvier $\left(\mathrm{Na}_{\mathrm{v}} 1.6\right.$; red) and paranodes (CASPR; green) in the fimbria of NL (F) and L (G) mice. H-I) Cumulative node length distribution in the fimbria (H) [448 NL and 520 L nodes; K-S D=0.25, $\mathrm{p}<0.0001$; inset, violin plot of node length, MWU test, $\mathrm{p}<0.0001$ ] and average fimbria node length per animal (I) in NL and L mice $[\mathrm{n}=4$ per group, $\mathrm{t}$-test, $\mathrm{t}=2.72, \mathrm{p}=0.03] .{ }^{*} \mathrm{p}<0.05, * * * * \mathrm{p}<0.0001$. Violin plots show the median (solid line) and interquartile range (dashed lines). Bars show mean $\pm \mathrm{SD}$. Scale bars represent $15 \mu \mathrm{m}(\mathrm{A}-\mathrm{C}), 1 \mu \mathrm{m}(\mathrm{F}-\mathrm{G})$. 

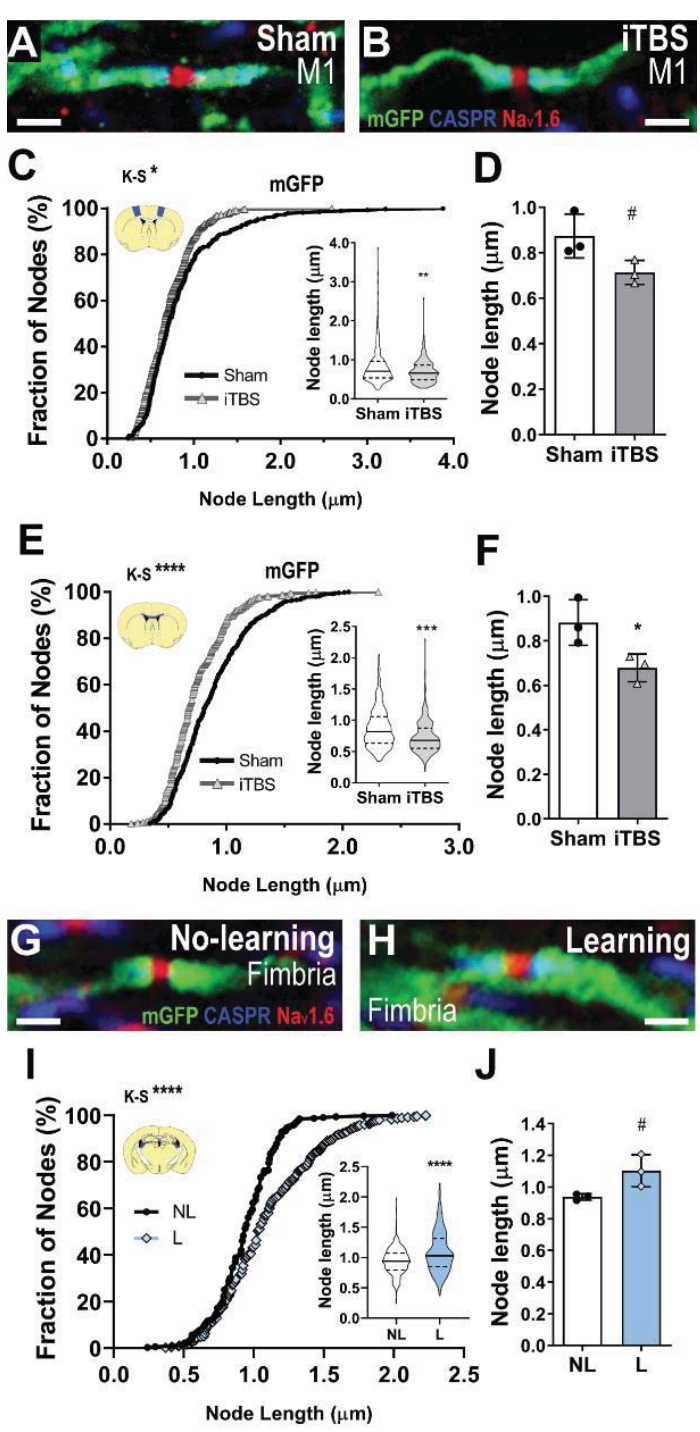

Figure 4. Nodal plasticity occurs between mature internodes.

A-B) Mature node of Ranvier $\left(\mathrm{Na}_{\mathrm{v}} 1.6\right.$; red) flanked by CASPR ${ }^{+}$paranodes (blue) and $\mathrm{mGFP}^{+}$ internodes (green) in M1 of Plp-CreER::Tau-mGFP mice, formed prior to sham (A) or iTBS (B) treatment. C-D) Cumulative mature node length distribution in M1 (C) [273 sham (black circles) and 325 iTBS (gray triangles) mature nodes; K-S D=0.11, $\mathrm{p}=0.03$; inset, violin plot of node length, MWU test, $\mathrm{p}=0.0019$ ] and average mature node length per sham (white bars) and iTBS (gray bars) animal (D) $[\mathrm{n}=3$ per group, t-test, $\mathrm{t}=2.52, \mathrm{p}=0.056]$. E-F) Cumulative mature node length distribution in the $\mathrm{CC}(\mathbf{E})$ [495 sham and 435 iTBS mature nodes; K-S D=0.22, $\mathrm{p}<0.0001$; inset, violin plot of node length, MWU test, $\mathrm{p}<0.0001]$ and average mature node length per individual sham-stimulated and iTBS mice $(\mathbf{F})[\mathrm{n}=3$ per group, $\mathrm{t}$-test, $\mathrm{t}=2.94$, $\mathrm{p}=0.04]$. G-H) Mature node of Ranvier $\left(\mathrm{Na}_{\mathrm{v}} 1.6\right.$; red) flanked by $\mathrm{CASPR}^{+}$paranodes (blue) and mGFP $^{+}$internodes (green) in the fimbria of Plp-CreER::Tau-mGFP in mice that underwent no-learning (NL; G) or learning (L; H) in the radial arm maze. I-J) Cumulative mature node length distribution in the fimbria (I) [319 NL (black circles) and $453 \mathrm{~L}$ (blue diamonds) mature nodes; K-S $\mathrm{D}=0.25, \mathrm{p}<0.0001$; inset, violin plot of node length, MWU test, $\mathrm{p}<0.0001$ ] and average mature node length per individual NL (white bars) and L (blue bars) mice $(\mathbf{J})[n=3$ per group, t-test, $\mathrm{t}=2.75, \mathrm{p}=0.051] .{ }^{*} \mathrm{p}<0.06,{ }^{*} \mathrm{p}<0.05, * * \mathrm{p}<0.01, * * * \mathrm{p}<0.001, * * * * \mathrm{p}<0.0001$. Violin plots show the median (solid line) and interquartile range (dashed lines). Bars show mean \pm SD. Scale bars represent $1 \mu \mathrm{m}$. 

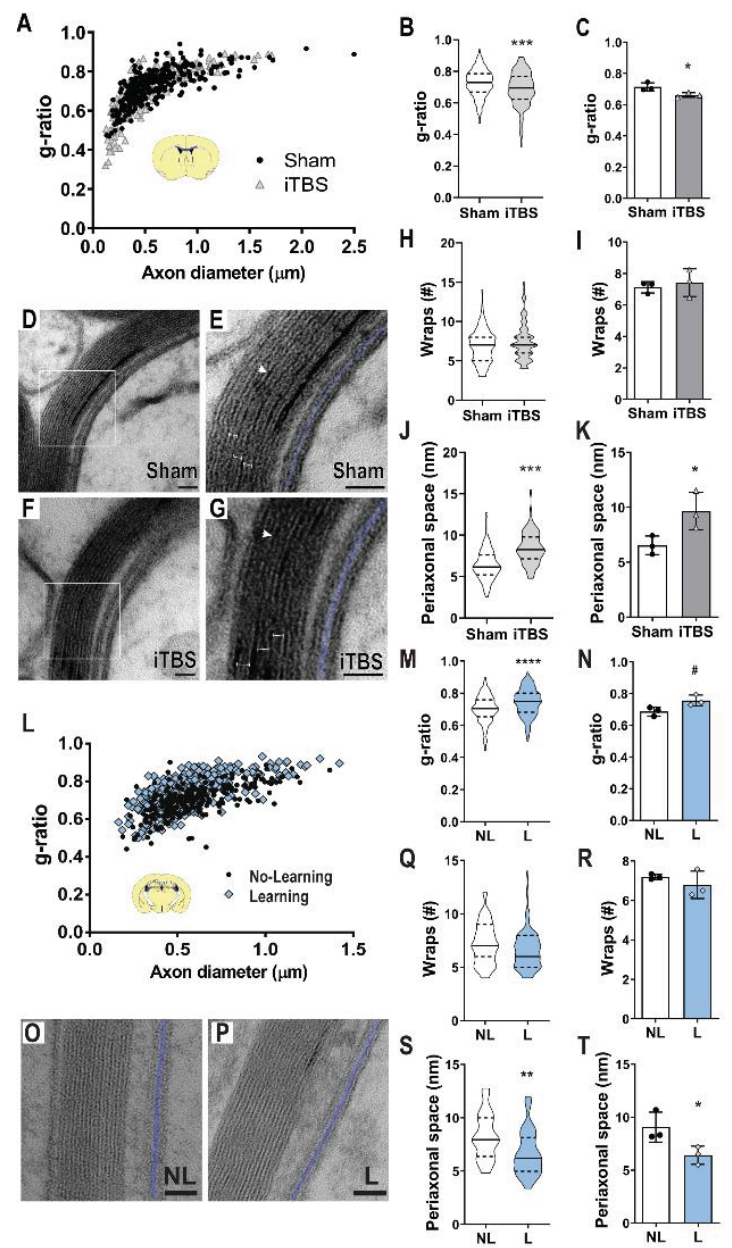

Figure 5. iTBS and spatial learning alter the size of the periaxonal space

A) Axonal diameter versus g-ratio for axons in the CC of sham-stimulated (black dots; $n=323$ axons) and iTBS (gray triangles; $\mathrm{n}=301$ axons) mice [Kolmogorov-Smirnov (K-S) test for gratio $\mathrm{D}=0.18, \mathrm{p}<0.0001]$. B) Violin plot of g-ratio [323 sham (white) and 301 iTBS (gray) axons; Mann Whitney U (MWU) test $\mathrm{p}<0.0001]$. C) Average g-ratio per individual sham and iTBS animal [t-test, $\mathrm{t}=2.98, \mathrm{p}=0.04]$. D-G) transmission electron microscopy (TEM) images of a myelinated axon in the CC of sham-stimulated $(\mathbf{D}, \mathbf{E})$ and iTBS $(\mathbf{F}, \mathbf{G})$ mice. White arrows $=$ major dense line. Blue shading = periaxonal space. $\mathbf{H}$ ) Violin plot of the number of myelin wraps per axon [104 sham and 125 iTBS axons; MWU test $\mathrm{p}=0.23]$. I) Average number of myelin wraps per individual sham and iTBS animal [t-test, $t=0.54, p=0.61]$. J) Violin plot of periaxonal space width 75 sham and 60 iTBS axons, MWU test $p<0.0001$ ). K) Average periaxonal space width per individual sham and iTBS animal [t-test, $t=2.84, p=0.04]$. L) Axon diameter versus g-ratio for axons in the fimbria of no-learning (NL; black dots) or learning (L; blue diamonds) mice [209 NL and $374 \mathrm{~L}$ axons; K-S test for g-ratio, K-S D=0.24, p<0.0001]. M) Violin plot of g-ratio [209 NL axons (white) and 374 L axons (blue); MWU test, $p<0.0001$ ]. N) Average g-ratio per individual NL and L animal [t-test, $\mathrm{t}=2.64, \mathrm{p}=0.057]$. O-P) TEM images of myelinated axon in the fimbria of $\mathrm{NL}(\mathbf{O})$ and $\mathrm{L}(\mathbf{P})$ mice. Q) Violin plot of the number of myelin wraps per axon [55 NL and $55 \mathrm{~L}$ axons; MWU test, $\mathrm{p}=0.10]$. R) Average number of myelin wraps per individual NL and $\mathrm{L}$ animal [t-test, $\mathrm{t}=0.98, \mathrm{p}=0.38$ ]. S) Violin plots of periaxonal space width [36 NL and $38 \mathrm{~L}$ axons; MWU test, $p=0.0023$ ]. T) Average periaxonal space width per individual NL and $\mathrm{L}$ animal [t-test, $\mathrm{t}=2.78, \mathrm{p}=0.04]$. Capped lines $=$ single myelin wrap. ${ }^{\#} \mathrm{p}<0.06,{ }^{*} \mathrm{p}<0.05, * * \mathrm{p}<0.01, * * * \mathrm{p}<0.001, * * * * \mathrm{p}<0.0001$. Violin plots show the median (solid line) and interquartile range (dashed lines). Bars show mean $\pm \mathrm{SD}$ for $\mathrm{n}=3$ animals per group. Scale bars $=25 \mathrm{~nm}(\mathrm{D}-\mathrm{G})$ or $50 \mathrm{~nm}(\mathrm{O}-\mathrm{P})$. 

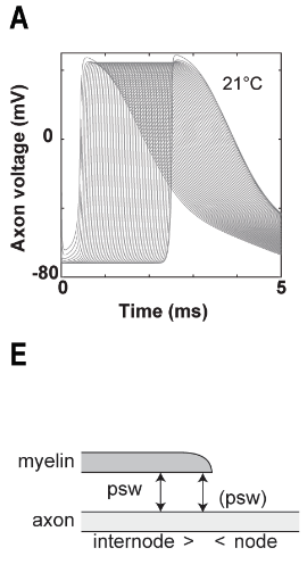

I

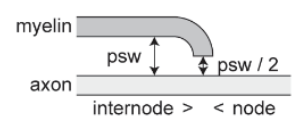

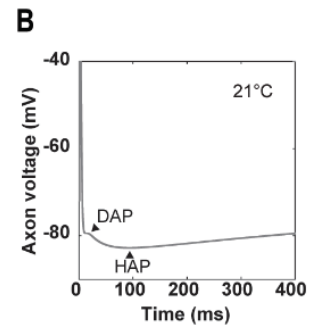

$\mathbf{F}$

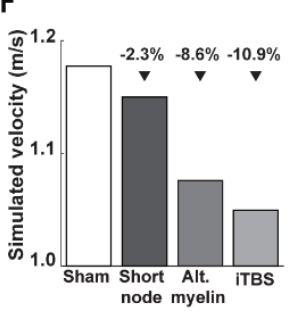

$J$

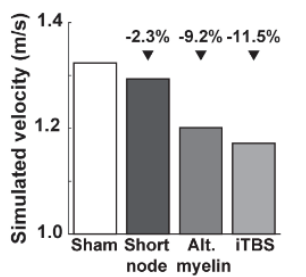

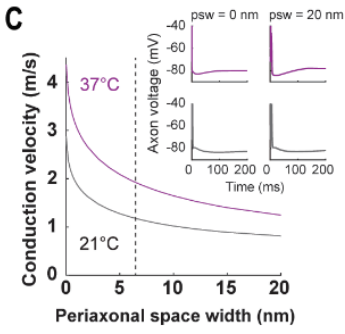

G

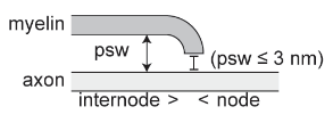

K

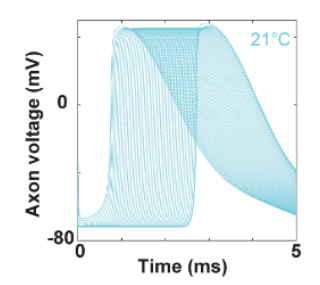

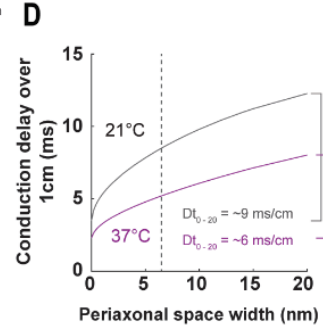

H

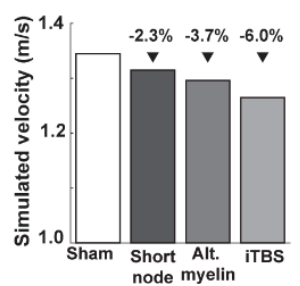

$\mathbf{L}$

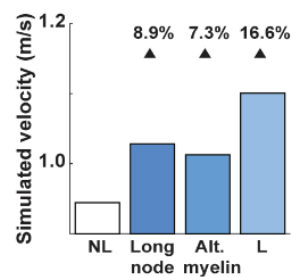

Figure 6. The size of the periaxonal space modulates conduction velocity

A) Action potentials simulated at consecutive callosal nodes at $21^{\circ} \mathrm{C}$. B) The extended timecourse of action potentials generated by the model at $21^{\circ} \mathrm{C}$, highlighting a slight depolarizing after-potential (DAP) and a hyperpolarizing after-potential (HAP). C) Simulated conduction velocity of callosal axons relative to periaxonal space width (psw) at $37^{\circ} \mathrm{C}$ (magenta) and $21^{\circ} \mathrm{C}$ (gray), dashed line indicates average $p s w$ following sham stimulation insets show action potential waveforms at the extremities of the tested range ( $p s w=0$ or $20 \mathrm{~nm})$ at $21^{\circ} \mathrm{C}$ and $37^{\circ} \mathrm{C}$. D) Conduction delay over $1 \mathrm{~cm}$ relative to $p s w$ at $21^{\circ} \mathrm{C}$ and $37^{\circ} \mathrm{C}$. E) Schematic showing model parameters in which $p s w$ at the paranode is uniform to internode $p s w$. F) Predicted conduction velocity of a sham stimulated (white) axon versus an axon with either the node length shortened, the periaxonal space widened or both (iTBS) using the model depicted in (E). G) Schematic showing model parameters in which $p s w$ at the paranode is set to $\leq 3 \mathrm{~nm}$. H) Predicted conduction velocity of a sham stimulated axon versus an axon with either the node length shortened, periaxonal space widened or both (iTBS) using the model depicted in (G). I) Schematic showing model parameters in which $p s w$ at the paranode is set to half internode $p s w$. J) Predicted conduction velocity of a sham stimulated axon versus an axon with either the node length shortened, periaxonal space widened or both (iTBS) using the model depicted in (I). K) Action potentials simulated at consecutive nodes within the fimbria at $21^{\circ} \mathrm{C}$. L) Predicted conduction velocity of a no-learning (NL) control axon within the fimbria (white) versus an axon with either longer nodes, a narrower periaxonal space or both (learning, L). 


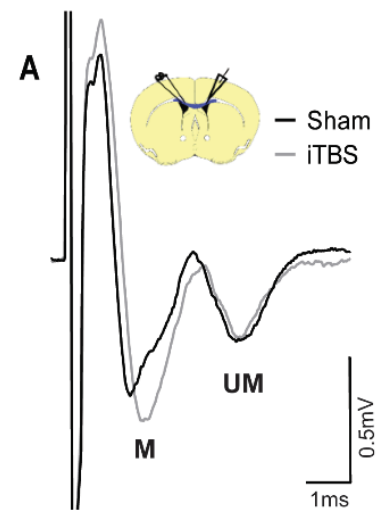

B
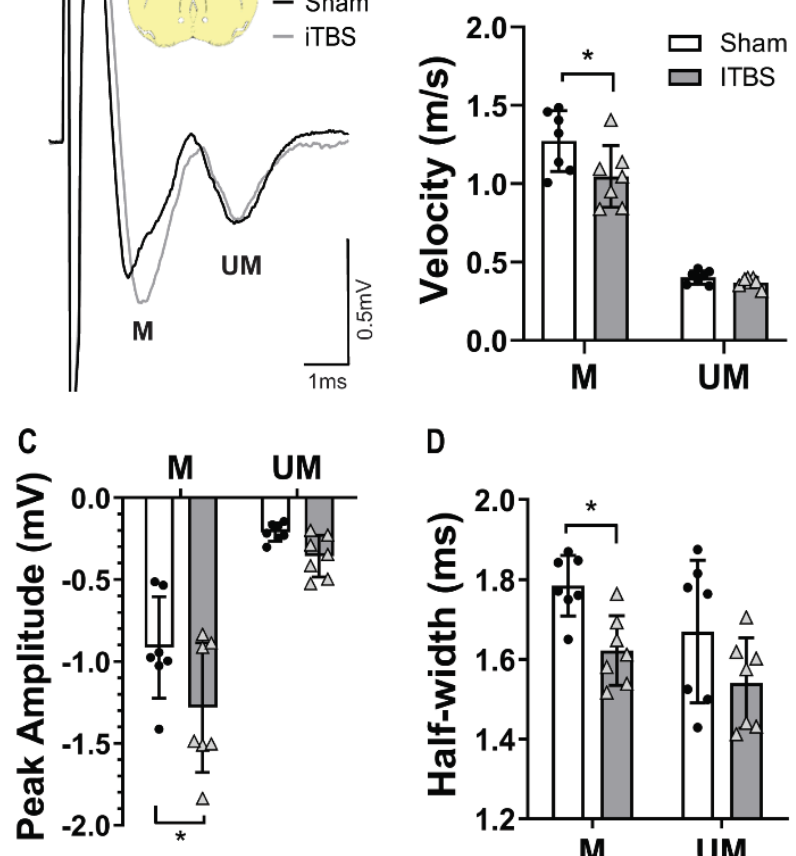

D

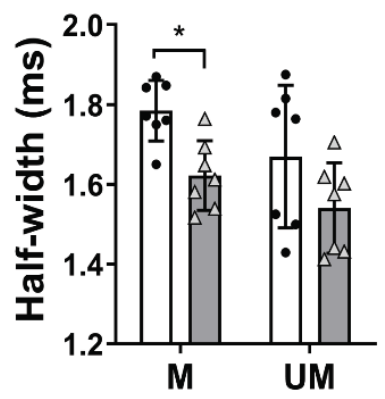

Figure 7. iTBS slows conduction velocity

A) Compound action potential (CAP) recorded in the CC of sham-stimulation (black) or iTBS (gray) mice. B) Conduction velocity of myelinated (M) and unmyelinated (UM) axons in sham-stimulated (black dots) or iTBS (gray triangles) mice [2-way ANOVA: interaction $\mathrm{F}(1,24)=3.37, \mathrm{p}=0.078$; axon population $\mathrm{F}(1,24)=211.1, \mathrm{p}<0.0001$; treatment $\mathrm{F}(1,24)=5.81$, $\mathrm{p}=0.023$. C) Peak amplitude of $\mathrm{M}$ and $\mathrm{UM}$ axons [2-way ANOVA: interaction $\mathrm{F}(1,24)=1.25$, $\mathrm{p}=0.27$; axon population $\mathrm{F}(1,24)=68.10, \mathrm{p}<0.0001$; treatment $\mathrm{F}(1,24)=6.75, \mathrm{p}=0.015]$. D) Half-width of CAP peak corresponding to $\mathrm{M}$ and UM axons [2-way ANOVA: interaction $\mathrm{F}(1,24)=0.13, \mathrm{p}=0.71$; axon population $\mathrm{F}(1,24)=4.63$, $\mathrm{p}=0.04$; treatment $\mathrm{F}(1,24)=10.22$, $\mathrm{p}=0.003]$. Bars show mean $\pm \mathrm{SD} .{ }^{*} \mathrm{p}<0.05$ by Bonferroni's post-test. 


\section{Methods:}

\section{Lead contact and materials availability}

Further information and requests for resources and reagents should be directed to and will be fulfilled by the lead contact, Kaylene Young (Kaylene.Young@utas.edu.au).

\section{Experimental model and subject details}

All animal experiments were approved by the University of Tasmania Animal Ethics Committee and carried out in accordance with the Australian code of practice for the care and use of animals for scientific purposes. All wildtype and transgenic mice were maintained on a C57BL/6J background. Heterozygous Plp-CreER transgenic mice (Doerflinger et al., 2003) were crossed with heterozygous Tau-lox-STOP-lox-mGFP-IRES-NLS-LacZ-pA (Tau-mGFP) Cre-sensitive reporter mice (Hippenmeyer et al., 2005)to generate double heterozygous offspring for the fluorescent labeling and tracing of oligodendrocytes. Homozygous Myrf loxPflanked exon 8 mice (Myrf flfl) (Emery et al., 2009) were crossed with heterozygous PdgfraCreER ${ }^{T M}$ transgenic mice (Kang et al., 2010) or homozygous Rosa26-YFP Cre-sensitive reporter mice (Srinivas et al., 2001) to produce Pdgfra-CreER ${ }^{T M}::$ Myrf $^{f l / f l}$ and Myrfflfl $::$ Rosa26-YFP offspring, respectively. These offspring were then intercrossed to generate Pdgfra-CreER $R^{T M}::$ Rosa26-YFP :: Myrf fl/fl $\left(\right.$ Myrf $\left.^{\text {fl/fl }}\right)$ and Rosa26-YFP :: Myrf fl/fl (control) mice for experiments. Male and female mice were housed in same sex groups (2-4 per cage), in individually ventilated cages (Optimice ${ }^{\circledR}$ ) on a $12 \mathrm{~h}$ light cycle (twilight phase starts 06:30, full lights on 07:00) at $21 \pm 2{ }^{\circ} \mathrm{C}$ with ad libitum access to standard rodent chow (Barrastoc rat and mouse pellets) and water. Experimental mice (P60-P90) weighed $18-35 \mathrm{~g}$ at the start of experiments and were randomly assigned to each treatment, but care was taken to ensure littermates were represented across treatment groups.

\section{Method details}


Transgenic lineage tracing and gene deletion

Cre, Rosa26-YFP and Tau-mGFP transgenes were detected by PCR as described by Cullen et al. (2019), and the Myrf floxed gene was detected as described by Emery et al. (2009). In brief, genomic DNA was extracted from ear biopsies by ethanol precipitation and PCR was performed using 50-100ng of gDNA with the following primer combinations: Cre 5' CAGGT CTCAG GAGCT ATGTC CAATt TACTG ACCGTA and Cre 3' GGTGT tATAAG CAATCC CCAGAA; GFP 5' CCCTG AAGTTC ATCTG CACCAC and GFP 3' TTCTC GTTGG GGTCT TTGCTC; Rosa26 wildtype 5’ AAAGT CGCTC TGAGT TGTTAT, Rosa26 wildtype 3' GGAGC GGGAG AAATG GATATG and Rosa26 YFP 5' GCGAA GAGTT TGTCC TCAACC; Myrf 5' AGgAG TGTTG TGGGA AGTGG and Myrf 3' CCCAG GCTGA AGATG GAATA.

To activate Cre-recombinase in oligodendrocyte precursor cells and induce targeted DNA recombination, Tamoxifen was dissolved in corn oil $(40 \mathrm{mg} / \mathrm{ml})$ by sonication at $21^{\circ} \mathrm{C}$ for $2 \mathrm{~h}$ and administered to adult mice (P83) by oral gavage at a dose of 300mg tamoxifen/kg body weight daily for four consecutive days. Plp-CreER :: Tau-mGFP mice were given a single dose of $50 \mathrm{mg} / \mathrm{kg}, 100 \mathrm{mg} / \mathrm{kg}$ or $300 \mathrm{mg} / \mathrm{kg}$ body weight to enable clear visualization of individual $\mathrm{mGFP}^{+}$internodes (Figure S1).

Low intensity repetitive transcranial magnetic stimulation

Low intensity repetitive transcranial magnetic stimulation (Li-rTMS) was delivered as per Cullen et al. (2019). Briefly, 600 pulses of intermittent theta burst stimulation (iTBS; 192s) was delivered using a custom made $120 \mathrm{mT}$ circular coil designed for rodent stimulation $(8 \mathrm{~mm}$ outer diameter, iron core) (Tang et al., 2016a; Tang et al., 2016b). Stimulation parameters were controlled by a waveform generator (Agilent Technologies) connected to a bipolar voltage programmable power supply (KEPCO BOP 100-4M, TMG test equipment). 
Experiments were conducted at $100 \%$ maximum power output $(100 \mathrm{~V})$ using custom monophasic waveforms $(400 \mu$ s rise time; Agilent Benchlink Waveform Builder). Mice were restrained using plastic body-contour shape restraint cones ( $0.5 \mathrm{~mm}$ thick; Able Scientific). The coil was manually held over the midline of the head with the back of the coil positioned in line with the front of the ears ( Bregma -3.0). Sham mice were positioned under the coil for 192s (as per iTBS), but no current was passed through the coil. Stimulation was carried out once daily, at the same time, for 14 consecutive days. Li-rTMS did not elicit observable behavioral changes in the mice during or immediately after stimulation.

\section{Spatial learning}

To induce spatial learning, adult (P60) male and female Plp-CreER :: Tau-mGFP or littermate control mice were administered a single dose of tamoxifen $(50 \mathrm{mg} / \mathrm{kg})$, then handled daily for two weeks before being trained in an 8-arm radial arm maze (RAM) task (Figure S3) over 14 days. 5 days prior to RAM training, non-learning and learning mice had their access to normal mouse chow restricted to $6 \mathrm{~h}$ per day but were given food rewards (Froot Loops ${ }^{\circledR}$ pieces) in their home cage. This food restriction protocol ensured that mice were maintained at $\sim 90 \%$ of their free feeding body weight and were motivated to seek out and consume the food rewards when available.

The RAM was carried out using the multi-maze system for mice (Ugo-Basile) in a radial 8arm configuration with spatial cues placed on each of the surrounding walls, $\sim 30 \mathrm{~cm}$ above the maze. RAM training consisted of two phases - a familiarization phase (days 1-3) and a learning phase (days 4-14) (Figure S3), and each mouse underwent 3 trials per day, with 60 minutes between each trial. During the familiarization phase, all arms of the RAM were closed off and an individual mouse was placed in the octagonal center of the maze with a single Froot Loop ${ }^{\circledR}$ (cut into 8 approximately equal sized pieces) for 10 minutes. No-learning control mice were 
exposed to the familiarization phase for the 14 days of the task, to ensure that they were subjected to the same environment and an equivalent level of handling and that they also received Froot Loops ${ }^{\circledR}$, but did not learn the RAM task (Figure S3A). Learning mice proceeded to undertake a learning phase, in which the 8 pieces of Froot Loop ${ }^{\circledR}$ were distributed, so that one piece was placed at the end of each arm of the RAM. An individual mouse was placed in the center of the maze and could explore the maze for 10 minutes (Figure S3B). Over the next 11 days, the mice learned that each arm contained a single food reward and that repeat entries would not result in another reward. Therefore, repeated entries into an arm in which the food reward had already been consumed was counted as an error, and the average number of errors made per trial was quantified as a measure of learning (Figure S3C). 24 hours after the final trial, mice were perfusion fixed and their brains collected and prepared for either immunohistochemistry or transmission electron microscopy.

\section{Tissue preparation and immunohistochemistry}

Mice were perfusion-fixed with 4\% paraformaldehyde (PFA; Sigma) (w/v) in phosphate buffered saline (PBS). Brains were cut into $2 \mathrm{~mm}$-thick coronal slices using a $1 \mathrm{~mm}$ brain matrix (Kent Scientific) before being post-fixed in $4 \%$ PFA at $21^{\circ} \mathrm{C}$ for 90 minutes. Tissue was cryoprotected overnight in $20 \%(\mathrm{w} / \mathrm{v})$ sucrose (Sigma) in PBS and snap frozen in OCT (ThermoFisher) for storage at $-80^{\circ} \mathrm{C} .30 \mu \mathrm{m}$ coronal brain cryosections, containing the primary motor cortex and underlying corpus callosum $(\sim$ Bregma +0.5$)$ or the dorsal region of the fimbria ( Bregma -1.5), were collected and processed as floating sections (Cullen et al., 2019). Primary and secondary antibodies were diluted in PBS blocking solution $[0.1 \%(\mathrm{v} / \mathrm{v})$ Triton X100 and $10 \%$ fetal calf serum in PBS] and applied to sections overnight at $4{ }^{\circ} \mathrm{C}$, unless staining involved the use of mouse anti-CC1 (1:100 Calbiochem), in which case antibodies were diluted in Tris buffered saline (TBS) blocking solution $[0.1 \%(\mathrm{v} / \mathrm{v})$ Triton X-100 and 10\% fetal calf serum in TBS]. Primary antibodies included goat anti-PDGFR $\alpha$ (1:200; R\&D Systems), rabbit 
anti-OLIG2 (1:400 Millipore), rat anti-GFP (1:2000; Nacalai Tesque), rabbit anti-NaV1.6 (1:500 Alomone Labs), mouse anti-CASPR (Clone K65/35; 1:200 NeuroMab). Secondary antibodies, which were conjugated to AlexaFluor $-488,-568$ or -647 (Invitrogen) were donkey anti-goat (1:1000), donkey anti-rabbit (1:1000), donkey anti-mouse (1:1000), and donkey antirat (1:500). Nuclei were labeled using Hoechst 33342 (1:1000; Invitrogen).

\section{Confocal microscopy and image quantification}

Confocal images were collected using an UltraView Nikon Ti Microscope with Volocity Software (Perkin Elmer). High magnification images (z-spacing of 0.5-2 $\mu \mathrm{m}$ ) were collected using standard excitation and emission filters for DAPI, FITC (AlexaFluor-488), TRITC (AlexaFluor-568) and CY5 (AlexaFluor-647), then stitched together to make a composite image of a defined region of interest. To quantify internode number and length for oligodendrocytes within the primary motor cortex (M1), high magnification images (40x objective) were collected through individual mGFP-labeled cortical oligodendrocytes $(0.5 \mu \mathrm{m}$ z-steps) that had a visible cell body. To quantify internodes in the corpus callosum (CC) and hippocampal fimbria, high magnification images $(60 \mathrm{x}$ objective) were collected $(0.5 \mu \mathrm{m} \mathrm{z}$ steps) and used to identify individual mGFP-labeled internodes that were flanked by CASPR ${ }^{+}$ paranodes. To measure node of Ranvier $\left(\mathrm{Na}_{\mathrm{v}} 1.6\right)$ and paranode (CASPR) length, high magnification (100x) single z-plane confocal images were collected from M1, the CC and the fimbria. Node and paranode lengths were only measured when a node and its flanking paranodes were intact within the single z-plane. For quantification of cell number, low magnification (20x objective) confocal z-stacks ( $2 \mu \mathrm{m}$ spacing) were collected through M1 and the $\mathrm{CC}$ and stitched together to make a composite image of a defined region of interest. All image analysis was carried out using Image $\mathrm{J}(\mathrm{NIH})$ by a researcher blind to experimental treatment. 


\section{Stimulated emission depletion (STED) microscopy}

$30 \mu \mathrm{m}$ coronal cryosections containing the corpus callosum $(\sim$ Bregma +0.5$)$ were collected and prepared as floating sections. Rabbit anti- $\mathrm{Na}_{\mathrm{v}} 1.6$ (1:500 Alomone Labs), mouse anti-CASPR (Clone K65/35; 1:200 NeuroMab) primary antibodies were diluted in PBS blocking solution $[0.1 \%(\mathrm{v} / \mathrm{v})$ Triton $\mathrm{X}-100$ and $10 \%$ fetal calf serum in PBS $]$ and applied to sections overnight at $4^{\circ} \mathrm{C}$. The sections were washed in PBS $(3 \times 10 \mathrm{~min})$ before overnight application $\left(4^{\circ} \mathrm{C}\right)$ of goat anti-mouse STAR Red (1:500, Abberior) and goat anti-rabbit STAR Orange (1:500, Abberior) secondary antibodies. The sections were mounted in antifade liquid mounting media (Abberior) and covered in a $170 \mu \mathrm{m}$ thick glass coverslip (ProSciTech, cat \# EMS72291-06).

STED imaging was performed using a two-color Abberior STEDYCON system (Abberior Instruments $\mathrm{GmbH}$ ) attached to a Nikon $\mathrm{NiE}$ confocal microscope equipped with $405 \mathrm{~nm}, 488$ $\mathrm{nm}, 561 \mathrm{~nm}$, and $640 \mathrm{~nm}$ pulsed excitation lasers, a pulsed $775 \mathrm{~nm}$ STED laser and a 100x oil immersion objective lens (N.A 1.4). Images were acquired using Abberior STEDYCON smart control software. For all images the pixel size and dwell time were kept consistent at 20nm and $10 \mu \mathrm{s}$, respectively. $561 \mathrm{~nm}$ and $640 \mathrm{~nm}$ excitation lasers were set to $10 \%$ power but STED laser power was optimally set to $100 \%$ (STAR orange, $561 \mathrm{~nm}$ ) or $56.2 \%$ (STAR red, $640 \mathrm{~nm}$ ). Single z-plane STED images were collected from the CC to enable the precise, high-resolution visualization of nodes of Ranvier $\left(\mathrm{Na}_{\mathrm{v}} 1.6\right)$ and their abutting paranodes (CASPR).

\section{Transmission electron microscopy}

Following 14 days of iTBS, sham stimulation or RAM training mice (P105 or P89) were perfused with Karnovsky's fixative $\left(2.5 \%\right.$ glutaraldehyde, $2 \%$ PFA, $0.25 \mathrm{mM} \mathrm{CaCl}_{2}, 0.5 \mathrm{mM}$ $\mathrm{MgCl}_{2}$ in $0.1 \mathrm{M}$ sodium cacodylate buffer). Brains were cut into $2 \mathrm{~mm}$-thick coronal slices using a $1 \mathrm{~mm}$ brain matrix (Kent Scientific) and post-fixed in Karnovsky's fixative for $2 \mathrm{~h}$ at $21^{\circ} \mathrm{C}$. The tissue blocks were rinsed and stored in $0.1 \mathrm{M}$ sodium cacodylate buffer overnight. The CC 
or hippocampal fimbria were dissected and incubated in $1 \%$ osmium tetroxide / $1.5 \%$ potassium ferricyanide $\left[\mathrm{OsO}_{4} / \mathrm{K}_{3} \mathrm{Fe}(\mathrm{III})(\mathrm{CN})_{6}\right]$ in $0.1 \mathrm{M}$ sodium cacodylate buffer in the dark for $2 \mathrm{~h}$ at $4^{\circ} \mathrm{C}$, before being dehydrated in ethanol and propylene oxide, and embedded in Epon812 resin. Ultrathin 70nm sections were cut using a Leica Ultra-cut UCT7 and stained with uranyl acetate and lead citrate. High resolution electron microscopy imaging was done at 80kV on a JEOL 1400-Flash (CC) or a Hitachi HT7700 (fimbria) transmission electron microscope. Sectioning, imaging and image analysis was carried out by an experimenter blind to the treatment group.

Image analysis was carried out using Image $\mathrm{J}(\mathrm{NIH})$. The proportion of myelinated axons and the g-ratio of myelinated axons [axon diameter / (axon + myelin diameter)] were measured from at least 100 axons from 5 images per animal. The number of myelin wraps was quantified by counting major dense lines for a minimum of 15 transected axons per mouse, from $n=3$ mice per treatment group. The average thickness of myelin wraps per axon, the width of the adaxonal inner tongue membrane and the width of the periaxonal space were measured from axons ensheathed by myelin that was a minimum of five wraps thick $(\geq 10$ transected axons per mouse, from $n=3$ mice per treatment group).

\section{Mathematical modeling}

In order to evaluate the effect on action potential propagation of experimentally observed microscopic changes in node length and myelin structure [data derived from the population mean from n=3 animals, (Figures 1, 2, 5 and S2) for iTBS experiments; and n=3-4 animals, (Figures 3, 5 and S3) for RAM experiments], we further adapted the mathematical model of action potential propagation in myelinated axons proposed by Richardson and colleagues [model 'C', their Fig. 1; (Bakiri et al., 2011; Richardson et al., 2000)]. A recent MATLAB (The MathWorks) implementation of that model by Cossell and colleagues can be downloaded 
from GitHub (https://github.com/AttwellLab/MyelinatedAxonModel) (Arancibia- Carcamo et al., 2017; Bakiri et al., 2011; Ford et al., 2015; Young et al., 2013). That package was downloaded in June 2018 and run on MATLAB R2016b.

The mathematical description of ion channels at nodes of Ranvier follows the Hodgkin-Huxley formalism. Briefly, nodes express three types of ion channels, a fast sodium channel $i_{N a}^{\text {fast }}$ responsible for the initiation of action potentials, a persistent sodium channel $i_{N a}^{\text {persistent }}$, and a slow potassium channel $i_{K}^{\text {slow }}$ responsible for the termination of action potentials. The kinetics of the three currents is derived from McIntyre et al. (2002). Briefly, $i_{N a}^{\mathrm{fast}}$ is written:

$$
i_{N a}^{\text {fast }}=g_{N a f} m^{3} h\left(V-E_{N a}\right)
$$

with $g_{N a f}$ the current conductance, $V$ the membrane voltage at the node, $E_{N a}=60 \mathrm{mV}$ the reversal potential for sodium ions, and $m$ and $h$ some gating variables. Following the HodgkinHuxley formalism, each gating variable $x$ in the model follows the generic equation:

$$
\frac{d x}{d t}=\alpha_{x}(1-x)-\beta_{x} x
$$

with $\alpha$ and $\beta$ some functions of $V$. For $i_{N a}^{\text {fast }}, \alpha$ and $\beta$ are given by:

$$
\begin{gathered}
\alpha_{m}=6.57 \frac{V+20.4}{1-e^{-\frac{V+20.4}{10.3}}} \\
\beta_{m}=-0.304 \frac{V+25.7}{1-e^{\frac{V+25.7}{9.16}}} \\
\alpha_{h}=-0.34 \frac{V+114}{1-e^{\frac{V+114}{11}}} \\
\beta_{h}=\frac{12.6}{1+e^{-\frac{V+31.8}{13.4}}}
\end{gathered}
$$

The persistent sodium current $i_{N a}^{\text {persistent }}$ is given by: 


$$
i_{N a}^{\text {persistent }}=g_{N a p} p^{3}\left(V-E_{N a}\right)
$$

with:

$$
\begin{gathered}
\alpha_{p}=0.0353 \frac{V+27}{1-e^{-\frac{V+27}{10.2}}} \\
\beta_{p}=-0.000883 \frac{V+34}{1-e^{(V+34) / 10)}} .
\end{gathered}
$$

The slow potassium current $i_{K}^{\text {slow }}$ is given by:

$$
i_{K}^{\text {slow }}=g_{K} s\left(V-E_{K}\right)
$$

with $E_{K}=-90 \mathrm{mV}$ the reversal potential for potassium ions and:

$$
\begin{aligned}
& \alpha_{s}=\frac{0.3}{1+e^{-\frac{V+53}{5}}} \\
& \beta_{s}=\frac{0.03}{1+e^{-(V+90)}} .
\end{aligned}
$$

Finally, all membranes contain a leak current given by:

$$
i_{L}=g_{L}\left(V-E_{L}\right)
$$

The Q10 for gates $m, h, p$ and $s$ are 2.2, 2.9, 2.2 and 3.0 respectively, described at $36^{\circ} \mathrm{C}$ [note that this has the effect of slowing down the kinetics of gates $m, h$ and $p$ with respect to McIntyre et al. (2002)]. All the other parameters of the model are given in Table S1 below. The same framework was used to simulate both corpus callosum and fimbria axons but with different parameter sets (see Table S1). Numerical values were chosen to match those observed in experiments or adapted from (Arancibia- Carcamo et al., 2017)). Myelin thickness was automatically calculated using:

$$
\text { Myelin thickness }=(d / g-d-2 p s w) / 2
$$


with $d$ the axon diameter, $g$ the g-ratio and psw the periaxonal space width. Myelin lamella periodicity was taken as myelin thickness divided by 6.5 so that the number of wraps is 7 in all conditions as observed experimentally (see Figure 5), assuming that the extracellular space between myelin lamellae comprises part of the periodicity and to account for the fact that there is no extracellular space contributing to the total width of the myelin on the most external lamella.

Unless stated otherwise, simulations were run using a time step of $0.1 \mu$ s and 51 nodes. Internode segments were chosen to be $<1 \mu \mathrm{m}(0.98 \mu \mathrm{m} ; \mathrm{N}=52$ segments per internode $)$ and we verified that this was sufficient to reach convergence for the conduction velocity over the whole range of simulated axons (Figure S6). Action potentials were triggered by a square pulse of $0.5 \mathrm{nA}$ lasting $10 \mu \mathrm{s}$. Ion channels at juxtaparanodes were not modelled, as is common in the field. When altering the length of the node of Ranvier (see below), the density of ion channels at the node was taken to be constant [see (Arancibia- Carcamo et al., 2017) for a systematic discussion of how this affects action potential conduction velocity].

To evaluate individually the effect of a node length reduction or the myelin sheath alterations on conduction velocity, we initially ran four sets of simulations. First, we used a parameter set matching the observations obtained in the sham condition (column 'Sham' in Table S1). We then ran the same simulations after reducing node lengths ('Short nodes'). Third, we ran simulations modifying the myelin sheath but keeping node length as per the sham condition ('Alt. myelin'). Finally, we ran a simulation with a fourth set of parameters implementing all the experimental changes observed following iTBS, i.e. a reduction in node length and alterations in the myelin sheath ('iTBS'). Simulations were run at $21^{\circ} \mathrm{C}$ and at $37^{\circ} \mathrm{C}$ (Figure 6, S5). We additionally investigated three different scenarios for conduction at the paranode. The periaxonal space width at the paranode was taken to be either [i] equal to the periaxonal space width in the internode; [ii] equal to the periaxonal space width under the internode if that 
is less than $3 \mathrm{~nm}$, but to be at most $3 \mathrm{~nm}$ otherwise; or [iii] equal to half the periaxonal space width in the internode (Figure 6, S5). Unless otherwise specified, scenario [i] is in use. Each paranode was taken to be 2 segments long $(1.96 \mu \mathrm{m}$ long).

To evaluate the functional consequence of myelin alterations, we additionally ran a set of simulations varying the periaxonal space width from 0 to $20 \mathrm{~nm}$ at both $21^{\circ} \mathrm{C}$ and $37^{\circ} \mathrm{C}$ (Figure 6). These simulations show that at $37^{\circ} \mathrm{C}$, the periaxonal space can tune action potential conduction velocity between $4.36 \mathrm{~m} / \mathrm{s}(\mathrm{psw}=0 \mathrm{~nm})$ and $1.25 \mathrm{~m} / \mathrm{s}(\mathrm{psw}=20 \mathrm{~nm}$; Figure 6). These numbers illustrate how potent and elegant this mechanism is, as it can speed up or slow down action potential conduction by a factor of 3.5 by making minor adjustments to the structure of myelinated axons. The functional consequences of this change to propagation speed at $37^{\circ} \mathrm{C}$ is to alter the arrival time of action potentials by $6 \mathrm{~ms}$ over a distance of $1 \mathrm{~cm}$ (Figure 6), enough to alter learning via spike-timing dependent plasticity for instance.

\section{Compound action potential recordings}

Compound action potential (CAP) recording and conduction-velocity measurement procedures were adapted from (Crawford et al., 2009). Briefly, the day after stimulation was complete, sham or iTBS-treated mice were killed by cervical dislocation and their brains rapidly dissected into ice-cold sucrose solution containing: $75 \mathrm{mM}$ sucrose, $87 \mathrm{mM} \mathrm{NaCl}, 2.5 \mathrm{mM} \mathrm{KCl}, 1.25$ $\mathrm{mM} \mathrm{NaH}{ }_{2} \mathrm{PO}_{4}, 25 \mathrm{mM} \mathrm{NaHCO} 3,7 \mathrm{mM} \mathrm{MgCl}_{2}$, and $0.95 \mathrm{mM} \mathrm{CaCl}_{2}$. Coronal vibratome sections $(400 \mu \mathrm{m} ; 2-3$ per animal spanning Bregma +0.8 and -0.2$)$ were generated using a Leica VT1200s vibratome and incubated at $\sim 32^{\circ} \mathrm{C}$ for $45 \mathrm{~min}$ in artificial cerebral spinal fluid (ACSF) containing $119 \mathrm{mM} \mathrm{NaCl}, 1.6 \mathrm{mM} \mathrm{KCl}, 1 \mathrm{mM} \mathrm{NaH}{ }_{2} \mathrm{PO} 4,26.2 \mathrm{mM} \mathrm{NaHCO} 3,1.4 \mathrm{mM}$ $\mathrm{MgCl}_{2}, 2.4 \mathrm{mM} \mathrm{CaCl}$ and $11 \mathrm{mM}$ glucose $(300 \pm 5 \mathrm{mOsm} / \mathrm{kg})$, before being transferred to $\sim 21^{\circ} \mathrm{C}$ ACSF saturated with $95 \% \mathrm{O}_{2} / 5 \% \mathrm{CO}_{2}$. 
CAPs were evoked by constant current, stimulus-isolated, square wave pulses $(200 \mathrm{~ms}$ duration, delivered at $0.2 \mathrm{~Hz}$ ), using a tungsten bipolar matrix stimulating electrode (FHC; MX21 AEW), and detected using glass recording electrodes (1-3 M $\Omega$ ) filled with $3 \mathrm{M} \mathrm{NaCl}$. To quantify CAP amplitude, the asymptotic maximum for the short-latency negative peak (myelinated peak, M; Figure 7) was first determined by placing the stimulating and recording electrodes $1 \mathrm{~mm}$ apart and varying the intensity of stimulus pulses $(0.3-4.0 \mathrm{~mA})$ using an external stimulus isolator (ISO-STIM 1D) before recording at $80 \%$ maximum stimulation. To enhance the signal-to-noise ratio, all quantitative electrophysiological analyses were conducted on waveforms that were the average of eight successive sweeps, amplified and filtered $(10 \mathrm{kHz}$ low pass bessel) using an Axopatch 200B amplifier (Molecular Devices), digitized at $100 \mathrm{kHz}$ and stored on disk for offline analysis.

The conduction velocity of myelinated (M) and unmyelinated (UM) axons in the CC was estimated by changing the distance between the stimulating and recording electrodes from 1 to $3 \mathrm{~mm}$, while holding the stimulus intensity constant ( $80 \%$ maximum). The peak latency of the $\mathrm{M}$ and UM axons was measured at each point and graphed relative to the distance separating the electrodes. A linear regression analysis was then performed to yield a slope that is the inverse of the velocity for each brain slice. The average velocity for both CAP components (M, UM) was then determined for each animal ( $n=7$ per group) and this value was used for statistical comparison.

\section{Statistical analyses}

The number of mice analyzed in each group $(n)$ or the number of cells, axons, nodes or internodes is indicated in the corresponding figure legends. Data distributions are presented as cumulative distribution plots and as violin plots with the median and interquartile range indicated. Data averaged per animal are presented as mean $\pm \mathrm{SD}$ with all data points shown. 
All statistical analyses were performed using Prism 8 (GraphPad Software). Data comparing two groups at a single time point were analyzed using a parametric two-tailed t-test $(n=$ mouse) or a non-parametric Mann-Whitney U test (MWU; $n=$ node, paranode, internode or axon). Cumulative distribution data were analyzed using a Kolmogorov-Smirnov (KS) test. Cell counts for lineage tracing, and compound action potential data were analyzed using a 2-way ANOVA with Bonferroni post-test. Learning in the RAM was analyzed using a repeated measures one-way ANOVA with a Geisser-Greenhouse correction to ensure equal variability and sphericity was not assumed, followed by a Bonferroni post-test. ANOVA main effects are given in the corresponding figure legends.

\section{Data code and availability}

Data for computational modelling are available from GitHub (https://github.com/JolivetLab).

\section{Key resources table:}

\begin{tabular}{|c|c|c|}
\hline REAGENT or RESOURCE & SOURCE & IDENTIFIER \\
\hline \multicolumn{3}{|l|}{ Antibodies } \\
\hline Rat (IgG2a) monoclonal (GF090R) anti-GFP & Nacalai Tesque, inc. & $\begin{array}{l}\text { Cat\# 04404-84, } \\
\text { RRID: AB_10013361 }\end{array}$ \\
\hline Mouse (IgG2b) monoclonal anti-APC (CC-1) & Millipore & $\begin{array}{l}\text { Cat\# OP80, } \\
\text { RRID:AB_2057371 }\end{array}$ \\
\hline Mouse (IgG1) monoclonal anti-CASPR (Clone K65/35) & $\begin{array}{l}\text { UC Davis/NIH } \\
\text { NeuroMab Facility }\end{array}$ & $\begin{array}{l}\text { Cat\# 75-001, } \\
\text { RRID:AB_2083496 }\end{array}$ \\
\hline Goat (IgG) polyclonal anti-mouse PDGFRa & R \& D Systems & $\begin{array}{l}\text { Cat\# AF1062, } \\
\text { RRID:AB_2236897 }\end{array}$ \\
\hline Rabbit polyclonal anti-OLIG2 & Millipore & $\begin{array}{l}\text { Cat\# AB9610, } \\
\text { RRID:AB_570666 }\end{array}$ \\
\hline Rabbit polyclonal anti-Nav1.6 & Alamone labs & $\begin{array}{l}\text { Cat\# ASC-009, } \\
\text { RRID:AB_2040202 }\end{array}$ \\
\hline Donkey anti-rat Alexa Fluor -488 & $\begin{array}{l}\text { Thermo Fisher } \\
\text { Scientific }\end{array}$ & $\begin{array}{l}\text { Cat\# A-21208, } \\
\text { RRID:AB_2535794 }\end{array}$ \\
\hline Donkey anti-mouse Alexa Fluor-568 & $\begin{array}{l}\text { Thermo Fisher } \\
\text { Scientific }\end{array}$ & $\begin{array}{l}\text { Cat\# A10037, } \\
\text { RRID:AB_2534013 }\end{array}$ \\
\hline Donkey anti-goat Alexa Fluor-568 & $\begin{array}{l}\text { Thermo Fisher } \\
\text { Scientific }\end{array}$ & $\begin{array}{l}\text { Cat\# A-11057, } \\
\text { RRID:AB_2534104 }\end{array}$ \\
\hline Donkey anti-rabbit Alexa Fluor -647 & $\begin{array}{l}\text { Thermo Fisher } \\
\text { Scientific }\end{array}$ & $\begin{array}{l}\text { Cat\# A-31573, } \\
\text { RRID:AB_2536183 }\end{array}$ \\
\hline Goat anti-mouse STAR RED & Abberior & $\begin{array}{l}\text { Cat\# STRED-1001- } \\
\text { 500UG, RRID:n/a }\end{array}$ \\
\hline Goat anti-rabbit STAR Orange & Abberior & $\begin{array}{l}\text { Cat\# STORANGE- } \\
\text { 1002-500UG, } \\
\text { RRID:n/a }\end{array}$ \\
\hline
\end{tabular}




\begin{tabular}{|c|c|c|}
\hline Hoechst 33342 & Invitrogen & $\begin{array}{l}\text { Cat\# H1399, } \\
\text { RRID:n/a }\end{array}$ \\
\hline \multicolumn{3}{|l|}{ Deposited Data } \\
\hline Conduction velocity model & This paper & $\begin{array}{l}\text { https://github.com/Jo } \\
\text { livetLab. }\end{array}$ \\
\hline \multicolumn{3}{|l|}{ Experimental Models: Organisms/Strains } \\
\hline C57BL/6J & $\begin{array}{l}\text { The Jackson } \\
\text { Laboratories }\end{array}$ & $\begin{array}{l}\text { IMSR Cat\# } \\
\text { JAX:000664, } \\
\text { RRID:IMSR_JAX:00 } \\
0664\end{array}$ \\
\hline Plp-CreER ${ }^{T}$ & $\begin{array}{l}\text { The Jackson } \\
\text { Laboratories }\end{array}$ & $\begin{array}{l}\text { Cat\# JAX:005975, } \\
\text { RRID:IMSR_JAX:00 } \\
5975\end{array}$ \\
\hline Tau-mGFP & $\begin{array}{l}\text { The Jackson } \\
\text { Laboratories }\end{array}$ & $\begin{array}{l}\text { Cat\# JAX:021162, } \\
\text { RRID:IMSR_JAX:02 } \\
1162\end{array}$ \\
\hline Myrf floxed & $\begin{array}{l}\text { The Jackson } \\
\text { Laboratories }\end{array}$ & $\begin{array}{l}\text { Cat\# JAX:010607, } \\
\text { RRID:IMSR_JAX:01 } \\
0607\end{array}$ \\
\hline Pdgfra-CreERTM & $\begin{array}{l}\text { The Jackson } \\
\text { Laboratories }\end{array}$ & $\begin{array}{l}\text { Cat\# JAX:018280, } \\
\text { RRID:IMSR_JAX:01 } \\
8280\end{array}$ \\
\hline Rosa26-YFP & $\begin{array}{l}\text { The Jackson } \\
\text { Laboratories }\end{array}$ & $\begin{array}{l}\text { Cat\# JAX:006148, } \\
\text { RRID:IMSR_JAX:00 } \\
6148\end{array}$ \\
\hline \multicolumn{3}{|l|}{ Oligonucleotides } \\
\hline $\begin{array}{l}\text { Cre 5' CAGGT CTCAG GAGCT ATGTC CAATT TACTG } \\
\text { ACCGTA }\end{array}$ & $\begin{array}{l}\text { Integrated DNA } \\
\text { Technologies }\end{array}$ & $\mathrm{n} / \mathrm{a}$ \\
\hline Cre 3' GGTGT TATAAG CAATCC CCAGAA & $\begin{array}{l}\text { Integrated DNA } \\
\text { Technologies }\end{array}$ & $\mathrm{n} / \mathrm{a}$ \\
\hline GFP 5' CCCTG AAGTTC ATCTG CACCAC & $\begin{array}{l}\text { Integrated DNA } \\
\text { Technologies }\end{array}$ & $\mathrm{n} / \mathrm{a}$ \\
\hline GFP 3' TTCTC GTTGG GGTCT TTGCTC & $\begin{array}{l}\text { Integrated DNA } \\
\text { Technologies }\end{array}$ & $\mathrm{n} / \mathrm{a}$ \\
\hline Rosa26 wildtype 5’ AAAGT CGCTC TGAGT TGTTAT & $\begin{array}{l}\text { Integrated DNA } \\
\text { Technologies }\end{array}$ & $\mathrm{n} / \mathrm{a}$ \\
\hline Rosa26 wildtype 3' GGAGC GGGAG AAATG GATATG & $\begin{array}{l}\text { Integrated DNA } \\
\text { Technologies }\end{array}$ & $\mathrm{n} / \mathrm{a}$ \\
\hline Rosa26 YFP 5' GCGAA GAGTT TGTCC TCAACC & $\begin{array}{l}\text { Integrated DNA } \\
\text { Technologies }\end{array}$ & $\mathrm{n} / \mathrm{a}$ \\
\hline Myrf 5’ AGGAG TGTTG TGGGA AGTGG & $\begin{array}{l}\text { Integrated DNA } \\
\text { Technologies }\end{array}$ & $\mathrm{n} / \mathrm{a}$ \\
\hline 'Myrf 3' CCCAG GCTGA AGATG GAATA & $\begin{array}{l}\text { Integrated DNA } \\
\text { Technologies }\end{array}$ & $\mathrm{n} / \mathrm{a}$ \\
\hline \multicolumn{3}{|l|}{ Software and Algorithms } \\
\hline Fiji (Image J) & $\begin{array}{l}\text { https://imagej.nih.gov/i } \\
\text { j/ }\end{array}$ & RRID:SCR_002285 \\
\hline GraphPad Prism (version 8) & $\begin{array}{l}\text { GraphPad Software, } \\
\text { Inc. }\end{array}$ & RRID:SCR_002798 \\
\hline pClamp (version 11) & Molecular Devices & RRID:SCR_011323 \\
\hline Matlab & Mathworks & RRID:SCR_001622 \\
\hline Volocity 3D Image Analysis Software & Perkin Elmer & RRID:SCR_002668 \\
\hline \multicolumn{3}{|l|}{ Other } \\
\hline Multi-Maze modular system (RAM) & Ugo Basile & Cat\# 41500 \\
\hline Kepco Bop 100-4M programmable power supply & TMG test equipment & $\mathrm{n} / \mathrm{a}$ \\
\hline BenchLink waveform builder & Agilent Technologies & Part \# 33521A \\
\hline
\end{tabular}


bioRxiv preprint doi: https://doi.org/10.1101/726760; this version posted May 3, 2020. The copyright holder for this preprint (which was not certified by peer review) is the author/funder, who has granted bioRxiv a license to display the preprint in perpetuity. It is made available under aCC-BY-NC-ND 4.0 International license.

\begin{tabular}{|l|l|l|}
\hline GM08 Gauss Meter, DC and $15 \mathrm{~Hz}-10 \mathrm{kHz}$ & $\begin{array}{l}\text { Hirst Magnetic } \\
\text { Instruments }\end{array}$ & $\mathrm{n} / \mathrm{a}$ \\
\hline Scientifica SliceScope Pro 1000 electrophysiology rig & Scientifica Ltd. & $\mathrm{n} / \mathrm{a}$ \\
\hline Axopatch 200B patch clamp amplifier & Axon Instruments & $\mathrm{n} / \mathrm{a}$ \\
\hline Iso-Stim 01D stimulus isolator & NPI Electronic & $\mathrm{n} / \mathrm{a}$ \\
\hline
\end{tabular}




\section{Supplementary material:}
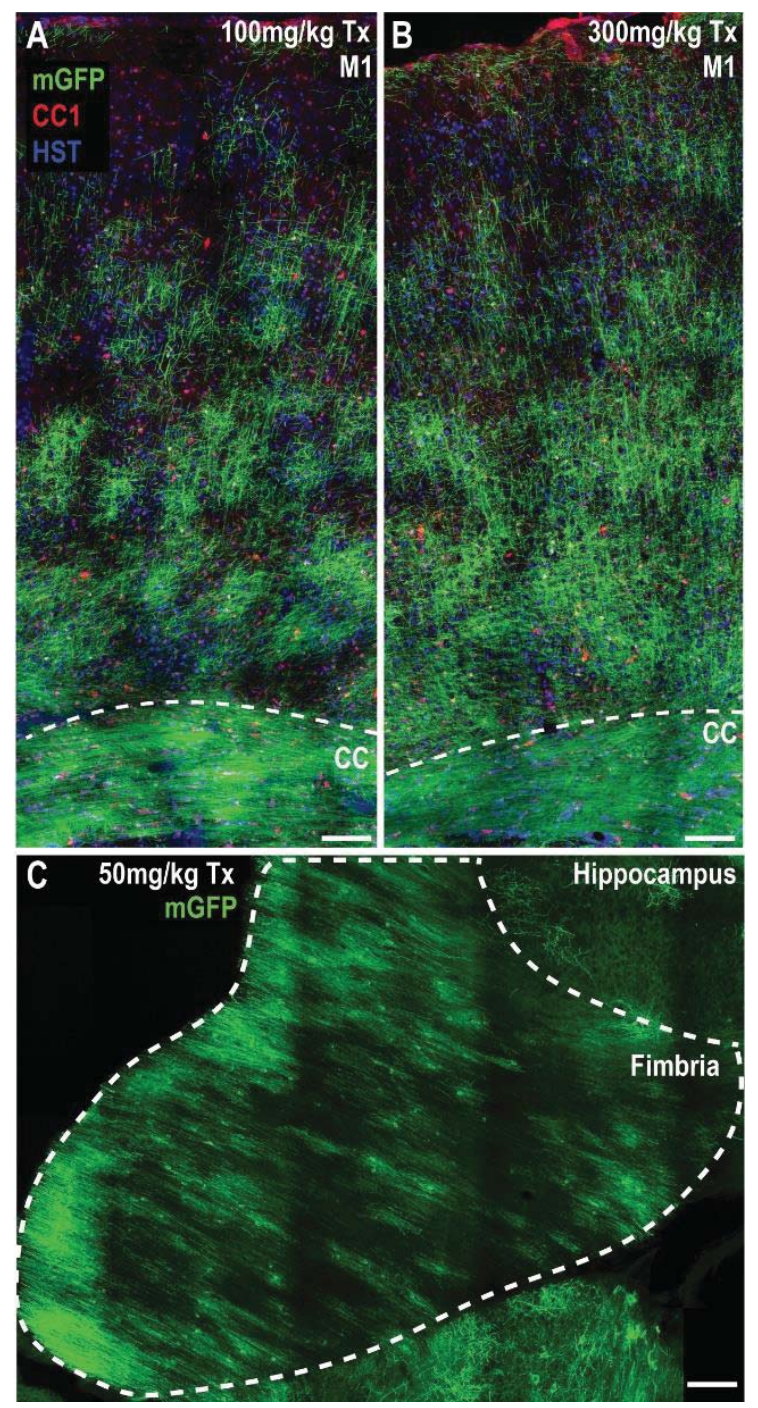

Figure S1. Mature, myelinating oligodendrocytes become mGFP-labeled following Tamoxifen administration to PlpCreER :: Tau-mGFP transgenic mice

A) Confocal image of M1 and the CC of a P80+15 Plp-CreER :: Tau-mGFP mouse that received a single $100 \mathrm{mg} / \mathrm{kg}$ dose of Tamoxifen (Tx), with its brain subsequently being stained to detect GFP (green), the oligodendrocyte marker CC1 (red) and Hoescht 33342 (blue). B) Confocal image of M1 and the CC of a P80+15 Plp-CreER:: Tau-mGFP mouse that received a single $300 \mathrm{mg} / \mathrm{kg}$ dose of Tamoxifen, with its brain being stained to detect GFP (green), CC1 (red) and Hoescht 33342 (blue). In mice that received only $100 \mathrm{mg} / \mathrm{kg}$ of Tamoxifen, it was possible to discern individual GFP-labeled $\mathrm{CC}^{+}$oligodendrocytes and their associated myelin internodes in the cortical layers. It was not possible to distinguish individual GFP-labeled $\mathrm{CC}^{+}$oligodendrocytes and their associated internodes within the CC of PlpCreER ::Tau$m G F P$ mice that received 100 or $300 \mathrm{mg} / \mathrm{kg}$ Tamoxifen. C) Confocal image of the hippocampal fimbria of a P60+15 Plp-CreER :: Tau-mGFP mouse that received a single $50 \mathrm{mg} / \mathrm{kg}$ dose of $\mathrm{Tx}$. It was not possible to reliably attribute $\mathrm{mGFP}^{+}$internodes to a single oligodendrocyte within the fimbria. Scale bars represent $100 \mu \mathrm{m}(\mathrm{A}-\mathrm{B}), 75 \mu \mathrm{m}(\mathrm{C})$. 
A

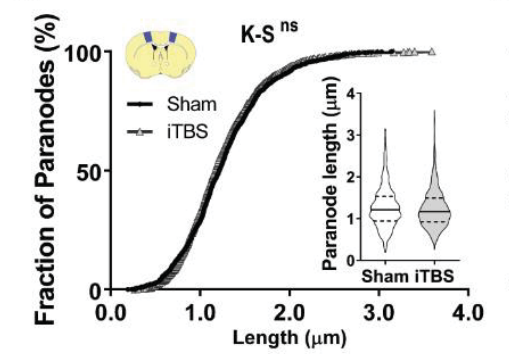

C
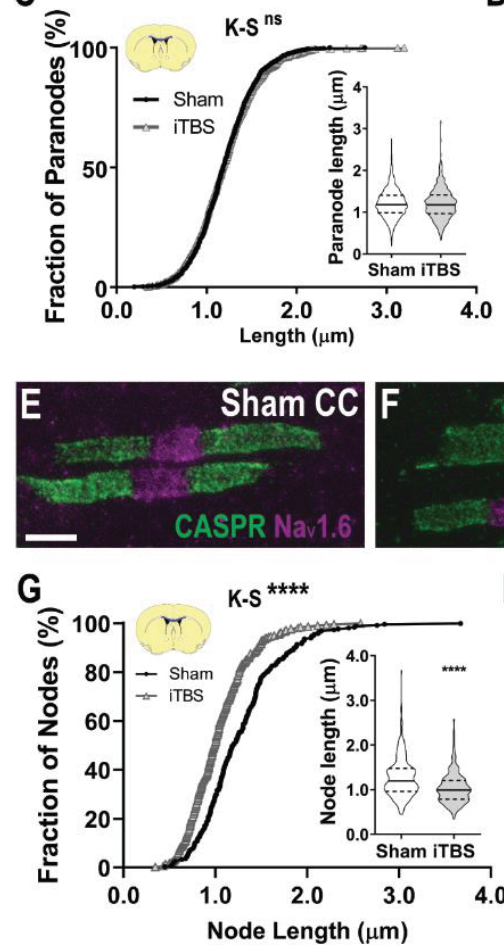

B

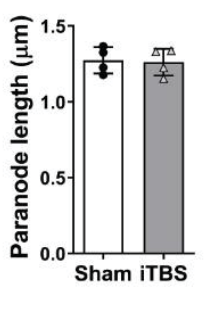

D

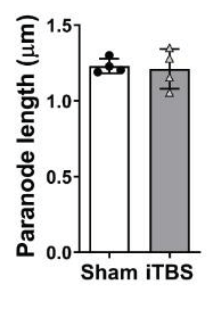

G

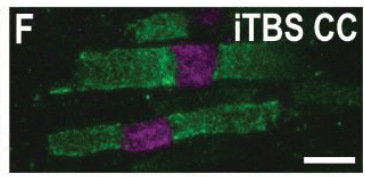

H

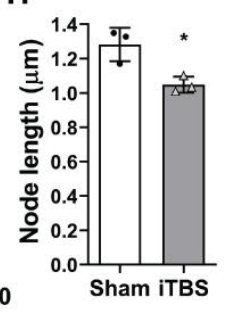

Figure S2. iTBS does not alter paranode length.

A) Cumulative paranode length distribution in M1 [1268 sham (black circles) and 1335 iTBS (gray triangles) paranodes; K-S test, K-S D $=0.053, \mathrm{p}=0.054$; Inset, violin plot of paranode length, MWU test $p=0.06]$. B) Average M1 paranode length per individual sham (white) and iTBS (gray) treated mouse [ $\mathrm{n}=4$ mice per group, $\mathrm{t}$-test, $\mathrm{t}=0.20, \mathrm{p}=0.84]$. C) Cumulative paranode length distribution in the CC [1099 sham and 1181 iTBS paranodes; K-S test, K-S $\mathrm{D}=0.03, \mathrm{p}=0.65$; Inset, violin plot of paranode length, MWU test $\mathrm{p}=0.73$ ] of mice receiving sham-stimulation and iTBS. D) Average CC paranode length per sham and iTBS stimulated animal [ $\mathrm{n}=4$ per group, $\mathrm{t}$-test, $\mathrm{t}=0.28, \mathrm{p}=0.78$ ]. $\mathbf{E - F}$ ) Representative STED image of nodes of Ranvier (Na 1.6 ; magenta) and paranodes (CASPR; green) from the CC of sham (E) and iTBS (F) mice. G) Cumulative distribution plot of node length in the STED imaged CC of sham and iTBS treated mice [269 sham and 325 iTBS nodes; K-S test, K-S D=0.27, p $<0.0001$; Inset, violin plot of paranode length, MWU test $\mathrm{p}<0.0001]$. H) Average CC node length (STED imaged) per sham and iTBS treated animal $[n=3$ per group, $t$-test, $t=3.73, p=0.02]$. Violin plots show the median (solid line) and interquartile range (dashed lines). Bars show mean $\pm \mathrm{SD}$. Scale bars $=1 \mu \mathrm{m}$. 

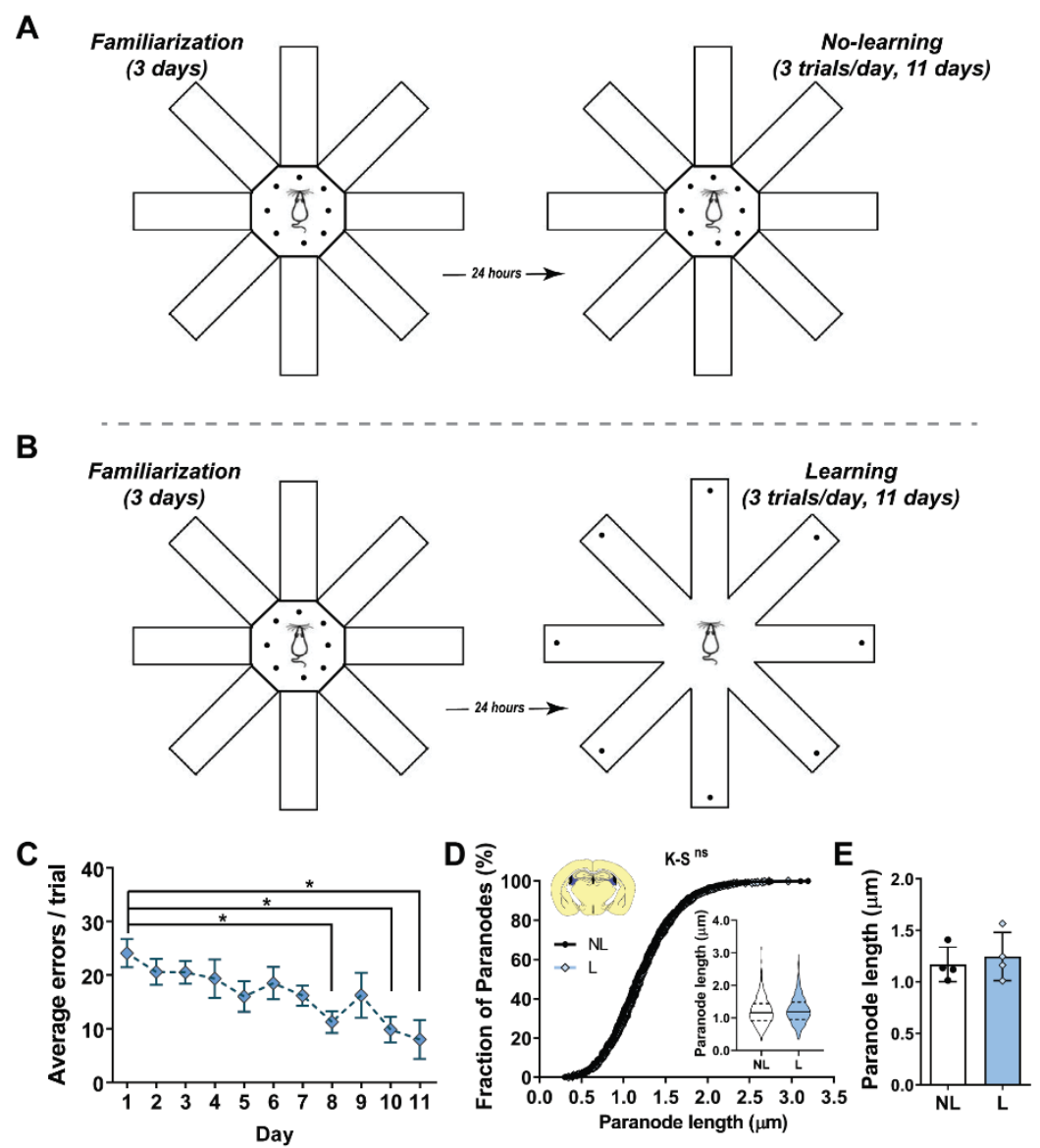

Figure S3. Spatial learning does not change paranode length in the fimbria.

A) Schematic outlining the radial arm maze (RAM) procedure during the first 3 days of familiarization to the maze and over the following 11 days for no-learning control mice. Each dot represents a piece of Froot Loop ${ }^{\circledR}$ that was used as a food reward stimulus and placed in the center of the maze for each trial over a total of 14 days. B) Schematic outlining the procedure during the familarization phase (first 3 days) and learning phase (last 11 days) of the RAM spatial learning task. Each dot represents a piece of Froot Loop ${ }^{\circledR}$ that was used as a food reward stimulus. Food rewards were placed in the center of the maze during the familiarization phase, but a single piece of Froot Loop ${ }^{\circledR}$ was placed at the end of each arm during each trial of the learning phase. Mice learned to enter each arm and consume the single food reward only once during a trial, with repeated entries into an arm in which the food reward was already consumed being recorded as a recall error. C) Quantification of the average number of errors made across 3 trials each day by mice learning the RAM task. Over the course of 11 days the mice progressively learned the task and made fewer errors [RM one-way ANOVA with Bonferroni post-test: $\mathrm{F}(1.84,5.521)=5.62, \mathrm{p}=0.048$. Mean \pm SEM for $\mathrm{n}=4$ mice]. D) Cumulative paranode length distribution in the fimbria of mice that underwent no-learning (NL; black dots) or learning (L; blue diamonds) in the RAM [682 no-learning and 724 learning paranodes; K-S test, K-S D=0.081, p=0.019; Inset, violin plot of paranode length, MWU test $\mathrm{p}=0.007]$. E) Average fimbria paranode length in NL (white) and L (blue) mice [ $\mathrm{n}=4$ mice per group, $\mathrm{t}$-test, $\mathrm{t}=0.52, \mathrm{p}=0.61]$. Violin plots show the median (solid line) and interquartile range (dashed lines). Bars show mean $\pm \mathrm{SD} . * \mathrm{p}<0.05$ 

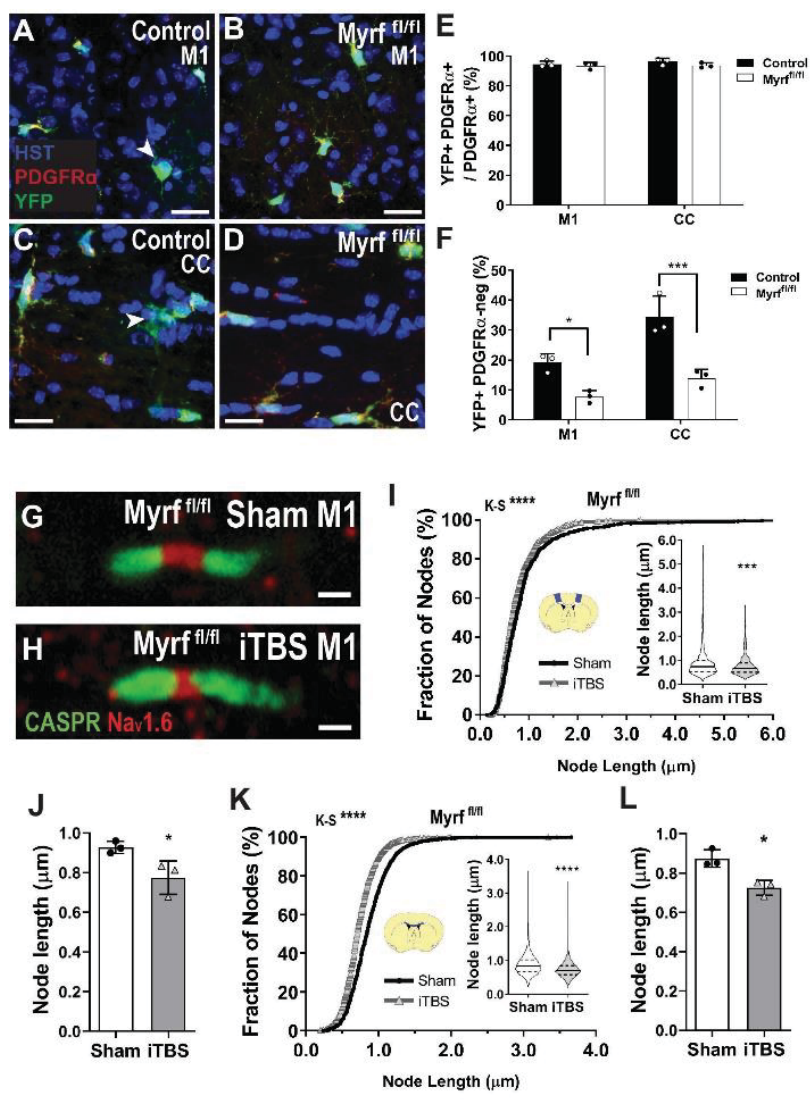

L

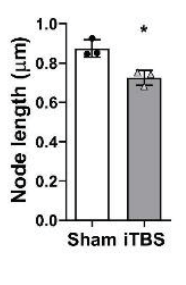

Figure S4. Preventing oligodendrogenesis does not affect iTBS induced node shortening.

Tamoxifen was administered to P60 control (Pdgfro-CreER ${ }^{T M}::$ Rosa26-YFP) and $\mathrm{Myrf}^{\mathrm{fl} / \mathrm{fl}}$ $\left(P d g f r \alpha-C r e E R^{T M}:: \operatorname{Rosa26-YFP}::\right.$ Myrf flfl $)$ mice to turn on expression of YFP in oligodendrocyte precursor cells (OPCs) and allow the lineage tracing of their progeny. Tamoxifen also resulted in the conditional deletion of Myrf from adult OPCs. A-D) Compressed confocal image from M1 (A-B) and CC (C-D) of P60+30 control (A, C) and $\operatorname{Myrf}^{\mathrm{fl} / \mathrm{fl}}(\mathbf{B}, \mathbf{D})$ mice stained to detect PDGFR $\alpha$ (red), YFP (green) and Hoescht 33342 (blue). E) The proportion of PDGFR $\alpha+$ OPCs that underwent recombination and become YFP-labeled in $\mathrm{M} 1$ and the $\mathrm{CC}$ of $\mathrm{P} 60+30$ control (black bars, white circles) and Myrf-deleted (white bars, black circles) mice [2-way ANOVA: region $\mathrm{F}(1,8)=0.57, \mathrm{p}=0.46$, gene $\mathrm{F}(1,8)=2.49, \mathrm{p}=0.15$, interaction $\mathrm{F}(1,8)=0.33, \mathrm{p}=0.57$. Mean $\pm \mathrm{SD}$. $\mathrm{n}=3$ mice per group]. F) Quantification of the proportion of PDGFR $\alpha$-neg YFP-labeled (and OLIG2 ${ }^{+}$) newly differentiated oligodendrocytes in $\mathrm{M} 1$ and the CC [2-way ANOVA with Bonferroni post-test: region $\mathrm{F}(1,8)=19.86, \mathrm{p}=0.0021$, gene $\mathrm{F}(1,8)=43.56, \mathrm{p}=0.0002$, interaction $\mathrm{F}(1,8)=3.56, \mathrm{p}=0.095]$. G-H) Node of Ranvier $\left(\mathrm{Na}_{\mathrm{v}} 1.6\right.$; red) in M1 of Myrf-deleted mice (Pdgfr $\left.\alpha-C r e E R^{T M}:: M y r f^{f l f l}\right)$ after 14 days of shamstimulation $(\mathbf{G})$ or iTBS (H). I-J) Cumulative node length distribution in M1 [C; 620 sham (black circles) and 727 iTBS (gray triangles) nodes; Kolmogorov-Smirnov (K-S) $\mathrm{D}=0.12$, $\mathrm{p}<0.0001$; inset violin plot of node length, Mann Whitney $U$ (MWU) test, $p<0.0001]$ and average node length per sham (white) or iTBS (gray) treated mice $(\mathbf{J}) ;[n=3$ mice per group, $t$ test, $\mathrm{t}=2.93, \mathrm{p}=0.04]$. K-L) Cumulative node length distribution in the CC (K) [1903 sham and 1670 iTBS nodes; K-S $\mathrm{D}=0.17, \mathrm{p}<0.0001$; inset violin plot of node length, MWU test, $\mathrm{p}<0.0001]$ and the average node length per animal $(\mathbf{L})$ of Myrf-deleted mice after shamstimulation or iTBS $[\mathrm{n}=3$ mice per group, $\mathrm{t}$-test, $\mathrm{t}=4.453, \mathrm{p}=0.01]$. Arrows indicate newborn oligodendrocytes. Violin plots denote the median (solid line) and interquartile range (dashed lines). $* \mathrm{p}<0.05, * * * \mathrm{p}<0.001, * * * * \mathrm{p}<0.0001$. Scale bars represent $13 \mu \mathrm{m}(\mathrm{A}-\mathrm{D}), 1 \mu \mathrm{m}(\mathrm{G}-\mathrm{H})$. 
A

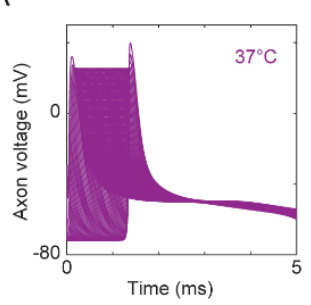

$E$

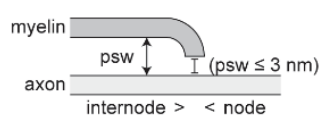

I

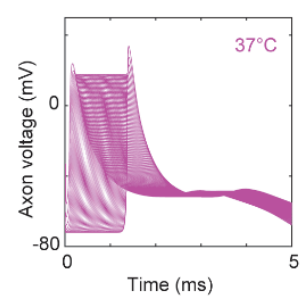

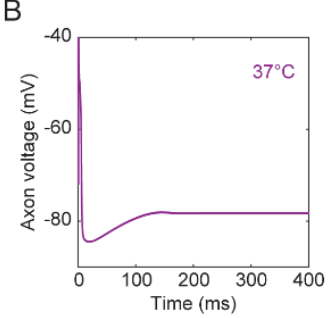

$\mathrm{F}$

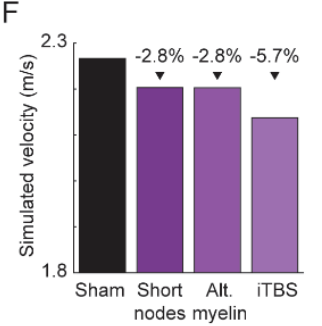

J

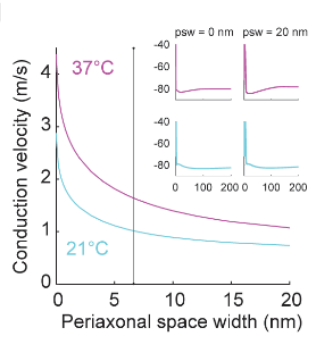

C

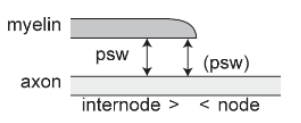

G
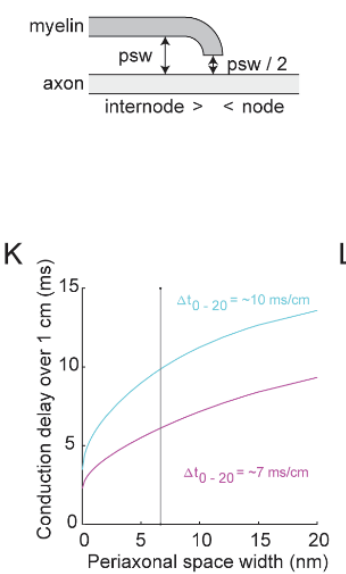

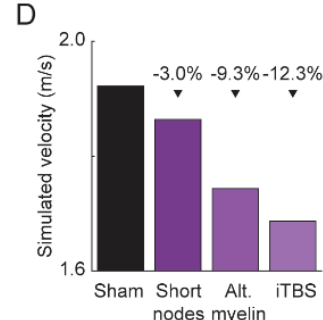

$\mathrm{H}$

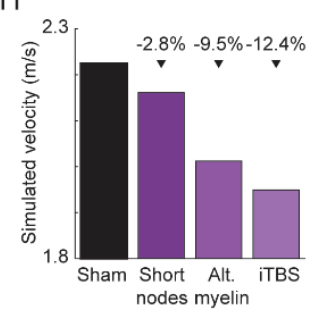

$\mathrm{L}$

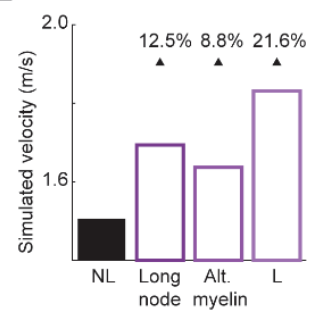

Figure S5. Mathematical simulation of conduction in myelinated central nervous system axons

A) Action potentials simulated at consecutive nodes in the corpus callosum at $37^{\circ} \mathrm{C}$. B) The extended time-course of action potentials generated by the model at $37^{\circ} \mathrm{C}$. C) Schematic showing model parameters in which periaxonal space width (psw) at the paranode is uniform to internode $p s w$. D) Predicted conduction velocity of a sham stimulated (white) axon versus an axon with either the node length shortened, the periaxonal space widened or both (iTBS, shades of magenta) using the model depicted in (C). E) Schematic showing model parameters in which $p s w$ at the paranode is set to $\leq 3 \mathrm{~nm}$. F) Predicted conduction velocity of a sham stimulated axon versus an axon with either the node length shortened, periaxonal space widened or both (iTBS) using the model depicted in (E). G) Schematic showing model parameters in which psw at the paranode is set to half the width in the internode. H) Predicted conduction velocity of a sham stimulated axon versus an axon with either the node length shortened, periaxonal space widened or both (iTBS) using the model depicted in (G). I) Action potentials simulated at consecutive nodes in the fimbria at $37^{\circ} \mathrm{C}$. J) Simulated conduction velocity of fimbria axons relative to periaxonal space width (psw) at $37^{\circ} \mathrm{C}$ (light magenta) and $21^{\circ} \mathrm{C}$ (cyan), solid line indicates average psw following iTBS, insets show action potential waveforms at the extremities of the tested range $(p s w=0$ or $20 \mathrm{~nm})$ at $21^{\circ} \mathrm{C}$ and $37^{\circ} \mathrm{C}$. K) Conduction delay over $1 \mathrm{~cm}$ relative to $p s w$ in the fimbria at $21^{\circ} \mathrm{C}$ and $37^{\circ} \mathrm{C}$. L) Predicted conduction velocity of a no-learning (NL) control axon within the fimbria at $37^{\circ} \mathrm{C}$ (white) versus an axon with either longer nodes, a narrower periaxonal space or both (learning, L). 

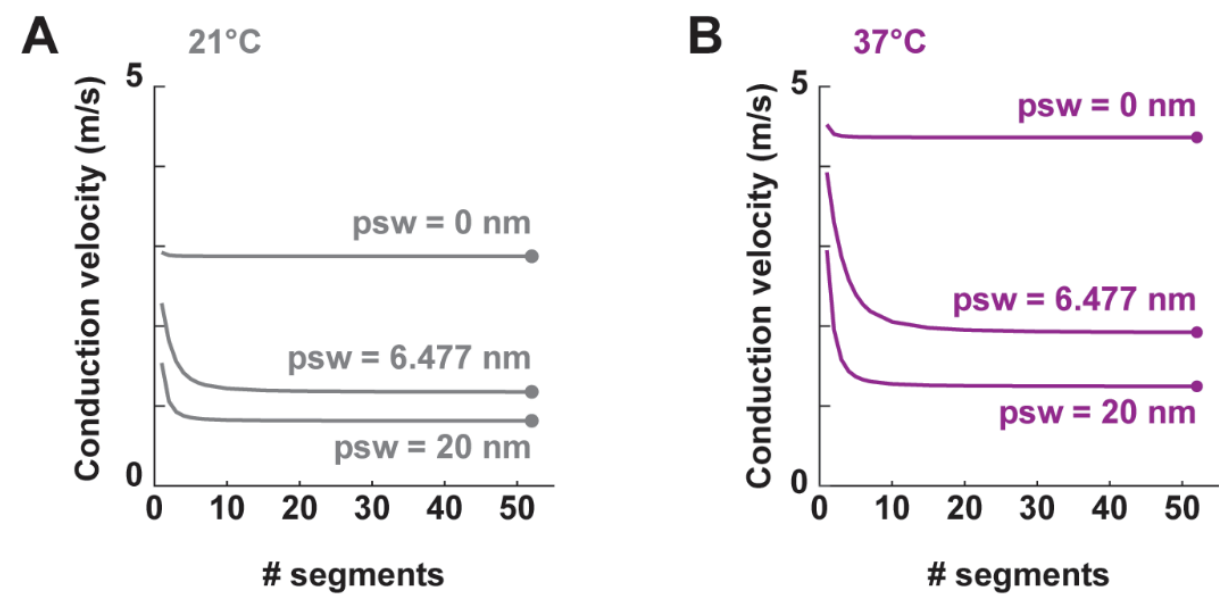

Figure S6. Controls for the convergence of conduction velocity in mathematical simulations Conduction velocity simulations were run at $21^{\circ} \mathrm{C}(\mathbf{A})$ or $37^{\circ} \mathrm{C}(\mathbf{B})$, inputting a periaxonal space width (psw) within the physiological range measured in the study $(6.477 \mathrm{~nm})$ or at two extremes ( $p s w=0 \mathrm{~nm}$ and $p s w=20 \mathrm{~nm})$, and used an increasing number of segments per internode. In all scenarios, using $\mathrm{N}=52$ segments (finishing dots), ensured that a stable prediction of the conduction velocity was reached irrespective of the width of the periaxonal space. 
Table S1. Parameters used in computational simulations of action potential conduction velocity.

\begin{tabular}{|c|c|c|c|c|c|c|c|c|c|}
\hline Parameter & & Sham & $\begin{array}{c}\text { Short } \\
\text { nodes* }\end{array}$ & $\begin{array}{c}\text { Alt. } \\
\text { myelin* }\end{array}$ & iTBS* & $\begin{array}{c}\text { No- } \\
\text { Learning }\end{array}$ & $\begin{array}{c}\text { Long } \\
\text { nodes* }\end{array}$ & $\begin{array}{c}\text { Alt. } \\
\text { myelin* }\end{array}$ & $\begin{array}{c}\text { Learning } \\
*\end{array}$ \\
\hline $\begin{array}{l}\text { Internode } \\
\text { length }\end{array}$ & $\mu \mathrm{m}$ & 50.32 & & & & 38.89 & & & \\
\hline $\begin{array}{c}\text { Axon } \\
\text { diameter }\end{array}$ & $\mu \mathrm{m}$ & 0.5894 & & & & 0.5938 & & & \\
\hline Node length & $\mu \mathrm{m}$ & 0.8364 & 0.7735 & & 0.7735 & 0.6644 & 0.8668 & & 0.8668 \\
\hline RMP & $\mathrm{mV}$ & -72 & & & & -72 & & & \\
\hline $\begin{array}{c}\text { Node } \\
\text { capacitance }\end{array}$ & $\mu \mathrm{F} / \mathrm{cm}^{2}$ & 0.9 & & & & 0.9 & & & \\
\hline $\begin{array}{l}\text { Internode } \\
\text { capacitance } \\
\text { Internode }\end{array}$ & $\mu \mathrm{F} / \mathrm{cm}^{2}$ & 0.9 & & & & 0.9 & & & \\
\hline $\begin{array}{c}\text { leak } \\
\text { conductance } \\
\left(g_{L}\right)\end{array}$ & $\mathrm{mS} / \mathrm{mm}^{2}$ & 0.1 & & & & 0.1 & & & \\
\hline$E_{L}$ & $\mathrm{mV}$ & -84 & & & & -84 & & & \\
\hline $\begin{array}{l}\text { Axoplasmic } \\
\text { resistivity }\end{array}$ & $\Omega \bullet \mathrm{m}$ & 0.7 & & & & 0.7 & & & \\
\hline $\begin{array}{l}\text { Periaxonal } \\
\text { resistivity }\end{array}$ & $\Omega \bullet \mathrm{m}$ & 0.7 & & & & 0.7 & & & \\
\hline $\begin{array}{l}\text { Periaxonal } \\
\text { space width }\end{array}$ & $\mathrm{nm}$ & 6.477 & & 8.487 & 8.487 & 8.265 & & 6.709 & 6.709 \\
\hline g-ratio & & 0.724 & & 0.6888 & 0.6888 & 0.7009 & & 0.7419 & 0.7419 \\
\hline $\begin{array}{l}\text { Number } \\
\text { lamellae }\end{array}$ & & 7 & & & & 7 & & & \\
\hline $\begin{array}{c}\text { Myelin } \\
\text { membrane } \\
\text { capacitance } \\
\text { Myelin } \\
\text { membrane } \\
\text { conductance }\end{array}$ & $\mathrm{mS} / \mathrm{mm}^{2}$ & 0.9 & & & & 0.9 & & & \\
\hline $\begin{array}{c}g_{N a f} \\
g_{N a p} \\
g_{K}\end{array}$ & $\begin{array}{l}\mathrm{mS} / \mathrm{mm}^{2} \\
\mathrm{mS} / \mathrm{mm}^{2} \\
\mathrm{mS} / \mathrm{mm}^{2}\end{array}$ & $\begin{array}{c}50 \\
0.05 \\
0.8\end{array}$ & & & & $\begin{array}{c}50 \\
0.05 \\
0.8\end{array}$ & & & \\
\hline
\end{tabular}

* Only detailed if different from the control (sham/no-learning) condition. 


\section{References:}

Aboul-Enein, F., Rauschka, H., Kornek, B., Stadelmann, C., Stefferl, A., Brück, W., Lucchinetti, C., Schmidbauer, M., Jellinger, K., and Lassmann, H. (2003). Preferential loss of myelin-associated glycoprotein reflects hypoxia-like white matter damage in stroke and inflammatory brain diseases. Journal of Neuropathology \& Experimental Neurology 62, 25-33.

Ainsworth, M., Lee, S., Cunningham, M.O., Traub, R.D., Kopell, N.J., and Whittington, Miles A. (2012). Rates and rhythms: A synergistic view of frequency and temporal coding in neuronal networks. Neuron 75, 572-583.

Almeida, R.G., and Lyons, D.A. (2017). On myelinated axon plasticity and neuronal circuit formation and function. J Neurosci 37, 10023-10034.

Arancibia- Carcamo, I.L., Ford, M.C., Cossell, L., Ishida, K., Tohyama, K., and Attwell, D. (2017). Node of ranvier length as a potential regulator of myelinated axon conduction speed. eLife 6, e23329.

Auer, F., Vagionitis, S., and Czopka, T. (2018). Evidence for myelin sheath remodeling in the cns revealed by $<$ em $>$ in\&\#xa0; vivo $<$ /em $>$ imaging. Current Biology 28, 549-559.e543.

Bakiri, Y., Káradóttir, R., Cossell, L., and Attwell, D. (2011). Morphological and electrical properties of oligodendrocytes in the white matter of the corpus callosum and cerebellum. The Journal of Physiology 589, 559-573.

Baraban, M., Koudelka, S., and Lyons, D.A. (2018). Ca 2+ activity signatures of myelin sheath formation and growth in vivo. Nature neuroscience 21, 19.

Battefeld, A., Popovic, M.A., de Vries, S.I., and Kole, M.H.P. (2019). High-frequency microdomain ca2+ transients and waves during early myelin internode remodeling. Cell Reports 26, 182-191.e185.

Bechler, M.E., Swire, M., and Ffrench-Constant, C. (2017). Intrinsic and adaptive myelination - a sequential mechanism for smart wiring in the brain. Developmental neurobiology.

Benchenane, K., Peyrache, A., Khamassi, M., Tierney, P.L., Gioanni, Y., Battaglia, F.P., and Wiener, S.I. (2010). Coherent theta oscillations and reorganization of spike timing in the hippocampal- prefrontal network upon learning. Neuron 66, 921-936.

Bhat, M.A., Rios, J.C., Lu, Y., Garcia-Fresco, G.P., Ching, W., Martin, M.S., Li, J., Einheber, S., Chesler, M., Rosenbluth, J., et al. (2001). Axon-glia interactions and the domain organization of myelinated axons requires neurexin iv/caspr/paranodin. Neuron 30, 369-383.

Burgess, N., Barry, C., and O'Keefe, J. (2007). An oscillatory interference model of grid cell firing. Hippocampus 17, 801-812.

Buzsaki, G. (2006). Rhythms of the brain (Oxford University Press).

Charles, P., Tait, S., Faivre-Sarrailh, C., Barbin, G., Gunn-Moore, F., Denisenko-Nehrbass, N., Guennoc, A.-M., Girault, J.-A., Brophy, P.J., and Lubetzki, C. (2002). Neurofascin is a glial receptor for the paranodin/caspr-contactin axonal complex at the axoglial junction. Current Biology 12, 217-220. 
Cohen, C.C.H., Popovic, M.A., Klooster, J., Weil, M.-T., Möbius, W., Nave, K.-A., and Kole, M.H.P. (2020). Saltatory conduction along myelinated axons involves a periaxonal nanocircuit. Cell 180, 311-322.e315.

Corcoba, A., Steullet, P., Duarte, J.M.N., Van de Looij, Y., Monin, A., Cuenod, M., Gruetter, R., and Do, K.Q. (2015). Glutathione deficit affects the integrity and function of the fimbria/fornix and anterior commissure in mice: Relevance for schizophrenia. International Journal of Neuropsychopharmacology 19.

Crawford, D.K., Mangiardi, M., and Tiwari-Woodruff, S.K. (2009). Assaying the functional effects of demyelination and remyelination: Revisiting field potential recordings. Journal of neuroscience methods 182, 25-33.

Cullen, C.L., Senesi, M., Tang, A.D., Clutterbuck, M.T., Auderset, L., O'Rourke, M.E., Rodger, J., and Young, K.M. (2019). Low-intensity transcranial magnetic stimulation promotes the survival and maturation of newborn oligodendrocytes in the adult mouse brain. Glia 67, 14621477.

Dimou, L., Simon, C., Kirchhoff, F., Takebayashi, H., and Götz, M. (2008). Progeny of olig2expressing progenitors in the gray and white matter of the adult mouse cerebral cortex. Journal of Neuroscience 28, 10434-10442.

Doerflinger, N.H., Macklin, W.B., and Popko, B. (2003). Inducible site- specific recombination in myelinating cells. genesis $35,63-72$.

Dupret, D., O'Neill, J., Pleydell-Bouverie, B., and Csicsvari, J. (2010). The reorganization and reactivation of hippocampal maps predict spatial memory performance. Nature Neuroscience 13, 995-1002.

Dupret, D., O’Neill, J., and Csicsvari, J. (2013). Dynamic reconfiguration of hippocampal interneuron circuits during spatial learning. Neuron 78, 166-180.

Dutta, D.J., Woo, D.H., Lee, P.R., Pajevic, S., Bukalo, O., Huffman, W.C., Wake, H., Basser, P.J., SheikhBahaei, S., Lazarevic, V., et al. (2018). Regulation of myelin structure and conduction velocity by perinodal astrocytes. Proceedings of the National Academy of Sciences 115, 11832-11837.

Emery, B., Agalliu, D., Cahoy, J.D., Watkins, T.A., Dugas, J.C., Mulinyawe, S.B., Ibrahim, A., Ligon, K.L., Rowitch, D.H., and Barres, B.A. (2009). Myelin gene regulatory factor is a critical transcriptional regulator required for cns myelination. Cell 138, 172-185.

Etxeberria, A., Hokanson, K.C., Dao, D.Q., Mayoral, S.R., Mei, F., Redmond, S.A., Ullian, E.M., and Chan, J.R. (2016). Dynamic modulation of myelination in response to visual stimuli alters optic nerve conduction velocity. The Journal of Neuroscience 36, 6937-6948.

Feldman, Daniel E. (2012). The spike-timing dependence of plasticity. Neuron 75, 556-571.

Ford, M., Alexandrova, O., Cossell, L., Stange-Marten, A., Sinclair, J., Kopp-Scheinpflug, C., Pecka, M., Attwell, D., and Grothe, B. (2015). Tuning of ranvier node and internode properties in myelinated axons to adjust action potential timing. Nature communications 6,8073 . 
Freeman, S.A., Desmazieres, A., Fricker, D., Lubetzki, C., and Sol-Foulon, N. (2016). Mechanisms of sodium channel clustering and its influence on axonal impulse conduction. Cellular and Molecular Life Sciences 73, 723-735.

Freeman, S.A., Desmazières, A., Simonnet, J., Gatta, M., Pfeiffer, F., Aigrot, M.S., Rappeneau, Q., Guerreiro, S., Michel, P.P., Yanagawa, Y., et al. (2015). Acceleration of conduction velocity linked to clustering of nodal components precedes myelination. Proceedings of the National Academy of Sciences 112, E321-E328.

Georgiou, J., Tropak, M.B., and Roder, J.C. (2004). Myelin-associated glycoprotein gene. In Myelin biology and disorders (Elsevier), pp. 421-467.

Gibson, E.M., Purger, D., Mount, C.W., Goldstein, A.K., Lin, G.L., Wood, L.S., Inema, I., Miller, S.E., Bieri, G., Zuchero, J.B., et al. (2014). Neuronal activity promotes oligodendrogenesis and adaptive myelination in the mammalian brain. Science 344, 1252304.

Halter, J.A., and Clark, J.W., Jr. (1993). The influence of nodal constriction on conduction velocity in myelinated nerve fibers. Neuroreport 4, 89-92.

Hill, R.A., Li, A.M., and Grutzendler, J. (2018). Lifelong cortical myelin plasticity and agerelated degeneration in the live mammalian brain. Nature Neuroscience 21, 683-695.

Hinman, J.D., Lee, M.D., Tung, S., Vinters, H.V., and Carmichael, S.T. (2015). Molecular disorganization of axons adjacent to human lacunar infarcts. Brain 138, 736-745.

Hippenmeyer, S., Vrieseling, E., Sigrist, M., Portmann, T., Laengle, C., Ladle, D.R., and Arber, S. (2005). A developmental switch in the response of drg neurons to ets transcription factor signaling. PLoS biology 3, e159.

Howell, O., Palser, A., Polito, A., Melrose, S., Zonta, B., Scheiermann, C., Vora, A., Brophy, P., and Reynolds, R. (2006). Disruption of neurofascin localization reveals early changes preceding demyelination and remyelination in multiple sclerosis. Brain 129, 3173-3185.

Huff, T.B., Shi, Y., Sun, W., Wu, W., Shi, R., and Cheng, J.-X. (2011). Real-time cars imaging reveals a calpain-dependent pathway for paranodal myelin retraction during high-frequency stimulation. PLoS One 6, e17176.

Hughes, E.G., Orthmann-Murphy, J.L., Langseth, A.J., and Bergles, D.E. (2018). Myelin remodeling through experience-dependent oligodendrogenesis in the adult somatosensory cortex. Nature Neuroscience 21, 696-706.

Jakovcevski, I., Filipovic, R., Mo, Z., Rakic, S., and Zecevic, N. (2009). Oligodendrocyte development and the onset of myelination in the human fetal brain. Frontiers in Neuroanatomy 3.

Jeffries, M.A., Urbanek, K., Torres, L., Wendell, S.G., Rubio, M.E., and Fyffe-Maricich, S.L. (2016). Erk1/2 activation in preexisting oligodendrocytes of adult mice drives new myelin synthesis and enhanced cns function. The Journal of Neuroscience 36, 9186-9200.

Jin, J., and Maren, S. (2015). Prefrontal-hippocampal interactions in memory and emotion. Frontiers in Systems Neuroscience 9. 
Jones, G.A., Norris, S.K., and Henderson, Z. (1999). Conduction velocities and membrane properties of different classes of rat septohippocampal neurons recorded in vitro. The Journal of Physiology 517, 867-877.

Kang, S.H., Fukaya, M., Yang, J.K., Rothstein, J.D., and Bergles, D.E. (2010). Ng2+ cns glial progenitors remain committed to the oligodendrocyte lineage in postnatal life and following neurodegeneration. Neuron 68, 668-681.

Kessaris, N., Fogarty, M., Iannarelli, P., Grist, M., Wegner, M., and Richardson, W.D. (2006). Competing waves of oligodendrocytes in the forebrain and postnatal elimination of an embryonic lineage. Nature Neuroscience 9, 173-179.

Klingseisen, A., Ristoiu, A.-M., Kegel, L., Sherman, D.L., Rubio-Brotons, M., Almeida, R.G., Koudelka, S., Benito-Kwiecinski, S.K., Poole, R.J., Brophy, P.J., et al. (2019). Oligodendrocyte neurofascin independently regulates both myelin targeting and sheath growth in the cns. Developmental Cell 51, 730-744.e736.

Koenning, M., Jackson, S., Hay, C.M., Faux, C., Kilpatrick, T.J., Willingham, M., and Emery, B. (2012). Myelin gene regulatory factor is required for maintenance of myelin and mature oligodendrocyte identity in the adult cns. The Journal of Neuroscience 32, 12528-12542.

Krasnow, A.M., Ford, M.C., Valdivia, L.E., Wilson, S.W., and Attwell, D. (2018). Regulation of developing myelin sheath elongation by oligodendrocyte calcium transients in vivo. Nature neuroscience 21, 24.

Li, C., Tropak, M.B., Gerlai, R., Clapoff, S., Abramow-Newerly, W., Trapp, B., Peterson, A., and Roder, J. (1994). Myelination in the absence of myelin-associated glycoprotein. Nature $369,747-750$.

Li, Q., Brus-Ramer, M., Martin, J.H., and McDonald, J.W. (2010). Electrical stimulation of the medullary pyramid promotes proliferation and differentiation of oligodendrocyte progenitor cells in the corticospinal tract of the adult rat. Neuroscience letters 479, 128-133.

Liu, J., Dietz, K., DeLoyht, J., Pedre, X., Kelkar, D., Kaur, J., Vialou, V., Lobo, M., Dietz, D., Nestler, E., et al. (2012). Impaired adult myelination in the prefrontal cortex of socially isolated mice. Nature neuroscience 15, 1621-1623.

Lu, Q.R., Sun, T., Zhu, Z., Ma, N., Garcia, M., Stiles, C.D., and Rowitch, D.H. (2002). Common developmental requirement for olig function indicates a motor neuron/oligodendrocyte connection. Cell 109, 75-86.

Makinodan, M., Rosen, K., Ito, S., and Corfas, G. (2012). A critical period for social experience-dependent oligodendrocyte maturation and myelination. Science 337, 1357-1360.

Markram, H., Gerstner, W., and Sjöström, P.J. (2012). Spike-timing-dependent plasticity: A comprehensive overview. Frontiers in Synaptic Neuroscience 4.

McIntyre, C.C., and Grill, W.M. (2002). Extracellular stimulation of central neurons: Influence of stimulus waveform and frequency on neuronal output. Journal of Neurophysiology 88, 15921604. 
McKenzie, I.A., Ohayon, D., Li, H., de Faria, J.P., Emery, B., Tohyama, K., and Richardson, W.D. (2014). Motor skill learning requires active central myelination. Science 346, 318-322.

Menichella, D.M., Majdan, M., Awatramani, R., Goodenough, D.A., Sirkowski, E., Scherer, S.S., and Paul, D.L. (2006). Genetic and physiological evidence that oligodendrocyte gap junctions contribute to spatial buffering of potassium released during neuronal activity. The Journal of Neuroscience 26, 10984-10991.

Micu, I., Plemel, J.R., Caprariello, A.V., Nave, K.-A., and Stys, P.K. (2017). Axo-myelinic neurotransmission: A novel mode of cell signalling in the central nervous system. Nature Reviews Neuroscience 19, 49.

Mitew, S., Gobius, I., Fenlon, L., McDougall, S.J., Hawkes, D., Xing, Y.L., Bujalka, H., Gundlach, A.L., Richards, L.J., Kilpatrick, T.J., et al. (2018). Pharmacogenetic stimulation of neuronal activity increases myelination in an axon-specific manner. Nature communications 9 , $1-16$.

Mount, C.W., and Monje, M. (2017). Wrapped to adapt: Experience-dependent myelination. Neuron 95, 743-755.

Nans, A., Einheber, S., Salzer, J.L., and Stokes, D.L. (2011). Electron tomography of paranodal septate-like junctions and the associated axonal and glial cytoskeletons in the central nervous system. Journal of Neuroscience Research 89, 310-319.

Negrón-Oyarzo, I., Espinosa, N., Aguilar-Rivera, M., Fuenzalida, M., Aboitiz, F., and Fuentealba, P. (2018). Coordinated prefrontal-hippocampal activity and navigation strategyrelated prefrontal firing during spatial memory formation. Proceedings of the National Academy of Sciences 115, 7123-7128.

O'Hare Doig, R.L., Chiha, W., Giacci, M.K., Yates, N.J., Bartlett, C.A., Smith, N.M., Hodgetts, S.I., Harvey, A.R., and Fitzgerald, M. (2017). Specific ion channels contribute to key elements of pathology during secondary degeneration following neurotrauma. BMC neuroscience 18 , 62.

Osanai, Y., Shimizu, T., Mori, T., Hatanaka, N., Kimori, Y., Kobayashi, K., Koyama, S., Yoshimura, Y., Nambu, A., and Ikenaka, K. (2018). Length of myelin internodes of individual oligodendrocytes is controlled by microenvironment influenced by normal and input-deprived axonal activities in sensory deprived mouse models. Glia 66, 2514-2525.

Pajevic, S., Basser, P.J., and Fields, R.D. (2014). Role of myelin plasticity in oscillations and synchrony of neuronal activity. Neuroscience 276, 135-147.

Peles, E., Nativ, M., Lustig, M., Grumet, M., Schilling, J., Martinez, R., Plowman, G.D., and Schlessinger, J. (1997). Identification of a novel contactin-associated transmembrane receptor with multiple domains implicated in protein-protein interactions. The EMBO Journal 16, 978988.

Pepper, R.E., Pitman, K.A., Cullen, C.L., and Young, K.M. (2018). How do cells of the oligodendrocyte lineage affect neuronal circuits to influence motor function, memory and mood? Frontiers in Cellular Neuroscience 12. 
Piscopo, D.M., Weible, A.P., Rothbart, M.K., Posner, M.I., and Niell, C.M. (2018). Changes in white matter in mice resulting from low-frequency brain stimulation. Proceedings of the National Academy of Sciences 115, E6339-E6346.

Pronker, M.F., Lemstra, S., Snijder, J., Heck, A.J.R., Thies-Weesie, D.M.E., Pasterkamp, R.J., and Janssen, B.J.C. (2016). Structural basis of myelin-associated glycoprotein adhesion and signalling. Nature Communications 7, 13584.

Quarles, R.H. (2007). Myelin- associated glycoprotein (mag): Past, present and beyond. Journal of neurochemistry 100, 1431-1448.

Reimer, M., McQueen, J., Searcy, L., Scullion, G., Zonta, B., Desmazieres, A., Holland, P., Smith, J., Gliddon, C., Wood, E., et al. (2011). Rapid disruption of axon-glial integrity in response to mild cerebral hypofusion. The Journal of neuroscience 31, 18185-18194.

Richardson, A.G., McIntyre, C.C., and Grill, W.M. (2000). Modelling the effects of electric fields on nerve fibres: Influence of the myelin sheath. Medical and Biological Enginerring and Computing 38, 438-446.

Rivers, L.E., Young, K.M., Rizzi, M., Jamen, F., Psachoulia, K., Wade, A., Kessaris, N., and Richardson, W.D. (2008). Pdgfra/ng2 glia generate myelinating oligodendrocytes and piriform projection neurons in adult mice. Nature neuroscience 11, 1392-1401.

Rosenbluth, J. (1995). Pathology of demyelinated and dysmyelinated axons. The Axon Structure, Function and Pathophysiology SG Waxman, JD Kocsis, and PK Stys, editors Oxford University Press, New York, NY.

Sampaio-Baptista, C., Khrapitchev, A., Foxley, S., Schlagheck, T., Scholz, J., Jbabdi, S., DeLuca, G., Miller, K., Taylor, A., Thomas, N., et al. (2013). Motor skill learning induces changes in white matter microstucture and myelination. Journal of Neuroscience 33, 1949919503.

Schneider, S., Gruart, A., Grade, S., Zhang, Y., Kroger, S., Kirchoff, F., Eichele, G., Delgardo Garcia, J., and Dimou, L. (2016). Decrease in newly generated oligodendrocytes leads to motor dysfunctions and changed myelin structures that can be rescued by transplanted cells. Glia 64, 2201-2218.

Seidl, A.H. (2014). Regulation of conduction time along axons. Neuroscience 276, 126-134.

Sherman, D.L., Tait, S., Melrose, S., Johnson, R., Zonta, B., Court, F.A., Macklin, W.B., Meek, S., Smith, A.J.H., Cottrell, D.F., et al. (2005). Neurofascins are required to establish axonal domains for saltatory conduction. Neuron 48, 737-742.

Simons, M., and Nave, K.A. (2015). Oligodendrocytes: Myelination and axonal support. Cold Spring Harb Perspect Biol 8, a020479.

Sirota, A., Montgomery, S., Fujisawa, S., Isomura, Y., Zugaro, M., and Buzsáki, G. (2008). Entrainment of neocortical neurons and gamma oscillations by the hippocampal theta rhythm. Neuron 60, 683-697. 
Srinivas, S., Watanabe, T., Lin, C.-S., William, C.M., Tanabe, Y., Jessell, T.M., and Costantini, F. (2001). Cre reporter strains produced by targeted insertion of eyfp and ecfp into the rosa26 locus. BMC developmental biology 1, 4.

Suzuki, A., Hoshi, T., Ishibashi, T., Hayashi, A., Yamaguchi, Y., and Baba, H. (2004). Paranodal axoglial junction is required for the maintenance of the nav1.6-type sodium channel in the node of ranvier in the optic nerves but not in peripheral nerve fibers in the sulfatidedeficient mice. Glia 46, 274-283.

Tang, A.D., Hong, I., Boddington, L.J., Garrett, A.R., Etherington, S., Reynolds, J.N., and Rodger, J. (2016a). Low-intensity repetitive magnetic stimulation lowers action potential threshold and increases spike firing in layer 5 pyramidal neurons in vitro. Neuroscience 335, 64-71.

Tang, A.D., Lowe, A.S., Garrett, A.R., Woodward, R., Bennett, W., Canty, A.J., Garry, M.I., Hinder, M.R., Summers, J.J., and Gersner, R. (2016b). Construction and evaluation of rodentspecific rtms coils. Frontiers in neural circuits 10.

Tripathi, R., Jackiewicz, M., McKenzie, I., Kougioumtzidou, E., Grist, M., and Richardson, W.D. (2017). Remarkable stability of myelinating oligodendrocytes in mice. Cell reports 21, 316-323.

Waxman, S.G., Kocsis, J.D., and Stys, P.K. (1995). The axon: Structure, function and pathophysiology, Oxford Scholarship Online edn (New York: Oxford University Press).

Wyss, J.M., Swanson, L.W., and Cowan, W.M. (1980). The organization of the fimbria, dorsal fornix and ventral hippocampal commissure in the rat. Anatomy and Embryology 158, 303316.

Xiao, L., Ohayon, D., McKenzie, I.A., Sinclair-Wilson, A., Wright, J.L., Fudge, A.D., Emery, B., Li, H., and Richardson, W.D. (2016). Rapid production of new oligodendrocytes is required in the earliest stages of motor skill learning. Nature neuroscience 19, 1210.

Yeung, M.S., Zdunek, S., Bergmann, O., Bernard, S., Salehpour, M., Alkass, K., Perl, S., Tisdale, J., Possnert, G., and Brundin, L. (2014). Dynamics of oligodendrocyte generation and myelination in the human brain. Cell 159, 766-774.

Young, K.M., Psachoulia, K., Tripathi, R.B., Dunn, S.-J., Cossell, L., Attwell, D., Tohyama, K., and Richardson, W.D. (2013). Oligodendrocyte dynamics in the healthy adult cns: Evidence for myelin remodeling. Neuron 77, 873-885. 